\title{
The evolution of a coupled ice shelf-ocean system under different climate states
}

\author{
Klaus Grosfeld ${ }^{\mathrm{a}, *}$, Henner Sandhäger ${ }^{\mathrm{b}, 1}$

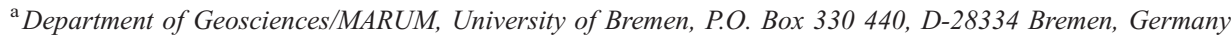 \\ ${ }^{\mathrm{b}}$ Alfred Wegener Institute Foundation for Polar and Marine Research, Bussestraße 24, D-27570 Bremerhaven, Germany
}

Received 26 May 2003; received in revised form 26 September 2003; accepted 21 November 2003

\begin{abstract}
Based on a new approach for coupled applications of an ice shelf model and an ocean general circulation model, we investigate the evolution of an ice shelf-ocean system and its sensitivity to changed climatic boundary conditions. Combining established 3D models into a coupled model system enabled us to study the reaction and feedbacks of each component to changes at their interface, the ice shelf base. After calculating the dynamics for prescribed initial ice shelf and bathymetric geometries, the basal mass balance determines the system evolution. In order to explore possible developments for given boundary conditions, an idealized geometry has been chosen, reflecting basic features of the Filchner-Ronne Ice Shelf, Antarctica. The model system is found to be especially sensitive in regions where high ablation or accretion rates occur. Ice Shelf Water formation as well as the build up of a marine ice body, resulting from accretion of marine ice, is simulated, indicating strong interaction processes.

To improve consistency between modeled and observed ice shelf behavior, we incorporate the typical cycle of steady ice front advance and sudden retreat due to tabular iceberg calving in our time-dependent simulations. Our basic hypothesis is that iceberg break off is associated with abrupt crack propagation along elongated anomalies of the inherent stress field of the ice body. This new concept yields glaciologically plausible results and represents an auspicious basis for the development of a thorough calving criterion.

Experiments under different climatic conditions (ocean warming of 0.2 and $0.5^{\circ} \mathrm{C}$ and doubled surface accumulation rates) show the coupled model system to be sensitive especially to ocean warming. Increased basal melt rates of $100 \%$ for the $0.5^{\circ} \mathrm{C}$ ocean warming scenario and an asymmetric development of ice shelf thicknesses suggest a high vulnerability of ice shelf regions, which represent pivotal areas between the Antarctic Ice Sheet and the Southern Ocean.
\end{abstract}

(C) 2004 Elsevier B.V. All rights reserved.

Keywords: Ice shelf-ocean interaction; Modeling; Climate change; Antarctica

\section{Introduction}

* Corresponding author. Tel.: +49-421-2187185; fax:+49-4212187040.

E-mail addresses: grosfeld@palmod.uni-bremen.de (K. Grosfeld), hsandhaeger@awi-bremerhaven.de (H. Sandhäger).

${ }^{1}$ Tel.: +49-471-48311785; fax: +49-471-48311797.
The freshwater budget of the world ocean is sustained by precipitation, river discharge, and runoff from land surfaces. Compensating for the freshwater loss mainly due to evaporation, these balance factors 
also govern the salinity regime of the ocean and, thus, contribute to water mass formation and modification. In the polar oceans, the seasonal sea ice evolution is an important factor, involving temporary freshwater storage and subsequent melting-induced release in regions remote from sea ice production areas. In this way, a thermohaline circulation of the ocean is maintained, whereby convection and sinking of dense water masses forces the overturning of the global ocean conveyor belt.

Compared to the intense redistribution process within the hydrological cycle, about $87 \%$ of the global freshwater is stored over long times in the world's ice sheets. Direct interaction processes between the ocean and the two far largest ice sheets, the Antarctic Ice Sheet and the Greenland Ice Sheet, occur primarily underneath the floating ice shelves, fringing especially in Antarctica half of the coastline. The intensity of these interactions is reflected in a mass loss of about $750 \mathrm{Gt} \mathrm{year}^{-1}$ due to melting at the Antarctic ice shelf bases (Jacobs et al., 1996), while about $2000 \mathrm{Gt}$ year $^{-1}$ get lost on average due to iceberg calving at the ice fronts (Jacobs et al., 1992).

Ice shelf-ocean interactions also have great influence on the individual characteristics of both climate components. Heat flux across the common interface, which is associated with melting and freezing, affects the physical and dynamic properties of the ice shelf, its mass balance, and its steady state geometry. On the other hand, heat and mass exchanges at the ice shelf bases considerably control the oceanographic condition especially in the Southern Ocean. By means of Ice Shelf Water (ISW) formation (ISW denotes a water mass of temperature below the surface freezing point), glacial meltwater is transformed into a water mass which is capable of contributing to deep and bottom waters (Foldvik et al., 1985). Hence, ocean and ice shelf together represent a closely coupled system, in which changes of one component affect the other component in a certain way, where direct feedback influences the whole system. Furthermore, each individual component is assessed to be climate sensitive (e.g., Vaughan and Doake, 1996; Oppenheimer, 1998), so that a high sensitivity of the coupled system can be expected for changes in climatic boundary conditions.

Some basic questions in this respect are: To what extent can ice shelf-ocean interaction influence wa- ter mass formation in the Southern Ocean? Is the thermohaline circulation in the Southern Ocean sensitive to changes in the ice shelf coverage of the Antarctic coastline? Do changes in ice shelf systems impact on the mass discharge from inland and, hence, the stability particularly of the West Antarctic Ice Sheet? Ultimate answers to such questions will only be possible if models considering a detailed quantitative description of the transition zone between ice sheet and open ocean, i.e., the ice shelf-ocean system, are available, and comprehensive simulations are possible.

The reaction of the coupled ice shelf-ocean system under consideration of expected feedbacks yet has to be investigated. For this purpose, it is necessary to study the intrinsic quantities like ice shelf and ocean dynamics adequately, and to quantify the exchange processes at the common interface, the ice shelf base. This will only be possible, for well-known static and dynamic boundary conditions, and forcing parameters of the coupled system.

In Fig. 1, an overview of the characteristics of the coupled ice shelf-ocean system is given. The schematic cross section illustrates most relevant parameters and processes necessary for a quantitative description of the system. It has to be emphasized, however, that the sketch represents a projection on a two-dimensional plane while most processes occur in the three-dimensional space and are much more complex than shown here. The ice shelf is nourished by ice flux over the grounding line, and by precipitation and basal accumulation. The rheology of the ice is controlled by the surface temperature, and the flow is directed seaward under the influence of gravity. Calving at the ice front, melting at the ice shelf base, evaporation, and surface runoff are the main processes for mass loss. All these factors together determine the dynamics and mass balance of the ice shelf and, thus, its shape and thickness distribution.

The ocean circulation in the sub-ice shelf cavity is affected by water mass formation on the continental shelf. Salty and cold water masses (High Salinity Shelf Waters: HSSW), which form during winter sea ice formation, drain into the ice shelf cavity and penetrate to the grounding line. Here, melting occurs due to the strong temperature contrast between seawater and ice shelf base. This contrast exceeds 


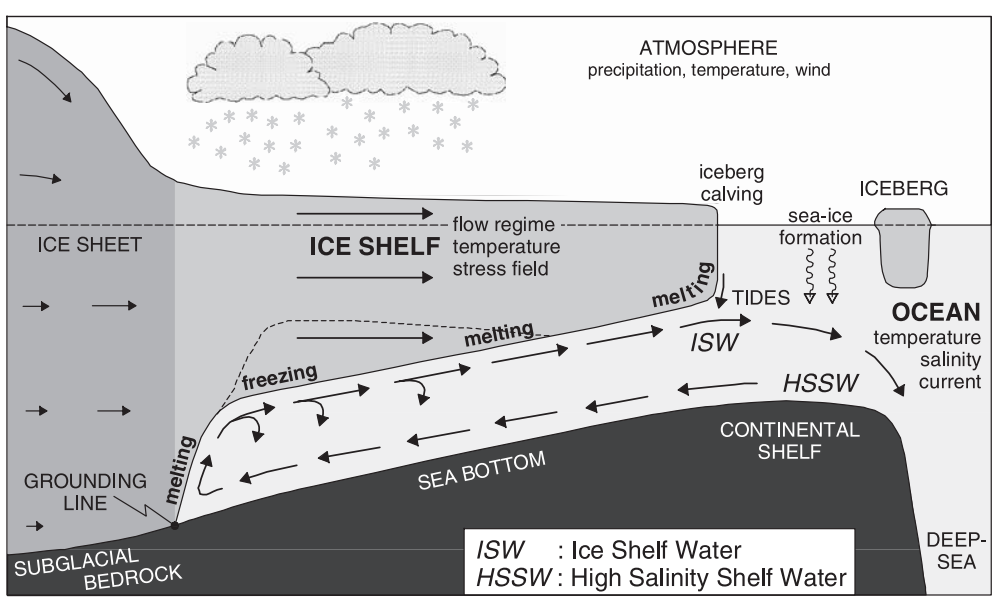

Fig. 1. Schematized cross section (2D projection) of a coupled ice shelf-ocean system. Shown are its main components, some basic influence quantities, and selected dynamical processes, governing the system evolution under the climatic boundary conditions.

$1.1{ }^{\circ} \mathrm{C}$ at $1500 \mathrm{~m}$ depth and is caused by the pressure dependence of the seawater freezing point, which decreases by $7.64 \times 10^{-4}{ }^{\circ} \mathrm{C}$ per $1000 \mathrm{~m}$ depth (Foldvik and Kvinge, 1974). Thus, even seawater at surface freezing point temperature, once subducted deep beneath an ice shelf, is warmer than the in situ freezing point, and can cool and yield up heat to perform ice shelf melting. ISW formed by mixing of meltwater with ambient water masses rises along the ascending ice shelf base until its in situ freezing point is reached. Consequently, ice crystals form in the water column and accumulate at the ice shelf base, leading to the formation of a marine ice body (Robin, 1979; Oerter et al., 1992). The residual water mass gains density due to salt release and partly recirculates. According to this so-called 'icepump' process (Lewis and Perkin, 1986), an overturning circulation establishes with inflow at the sea floor and outflow along the ascending ice shelf base. In general, a three-dimensional circulation regime predominates, including both vertical and horizontal inflow-outflow pattern. Outflowing ISW mixes with Circumpolar Deep Water variants at the continental shelf break, contributing to the formation of deep and bottom water.

Since access to ice shelf base and sub-ice shelf cavity require high logistic efforts, an auspicious way for studying the interaction processes and their changes with different climatic boundary conditions is by numerical model simulation. Up to date, separate sensitivity studies for either component of the ice shelf-ocean system have been performed. In the case of ocean models, the impact of changing ocean temperature in ice shelf cavities has been investigated, using 1D-plume models (Jenkins, 1991), 2D-vertical overturning thermohaline models (Hellmer and Jacobs, 1995) and 3D-ocean general circulation models (Grosfeld and Gerdes, 1998; Williams et al., 1998b, 2002). An overview of the different model concepts is given by Williams et al. (1998a). Although all studies are based on different assumptions of warming rate (variations between 0.25 and $3{ }^{\circ} \mathrm{C}$ are investigated), they all found an increased mass exchange at the ice shelf base. This is not surprising, but demonstrates the vulnerability of ice shelves to ocean warming.

Similar implications result from the few numerical simulations of ice shelf evolution under different climate boundary conditions. A 2D-horizontal ice shelf model was used by Determann (1991) to estimate the changes in steady state ice geometry and dynamics dependent on prescribed basal mass balances. Lingle et al. (1991) applied a flow-band model to determine a possible ice shelf response to $\mathrm{CO}_{2}$-induced climate warming. Their results range from slight ice body thickening to rapid thinning during the 175 - to 600 -year simulations, depending primarily on whether increasing surface temperatures and accumulation rates are accompanied by increased basal melt rates (linearly up to $2 \mathrm{~m}$ year $^{-1}$ ). 
It is not within the scope of this study to evaluate or distinguish between different scenarios and to identify a most realistic assumption. Here, we investigate the response of the coupled ice shelf-ocean system to changes in its surface and basal mass balances. This not only includes the impact on the hydrography, but also considers the dynamic response of the ice shelf. The latter could be influential to ice sheet discharge and, hence, to global sea level (MacAyeal, 1992). However, our study does not address a particular Antarctic ice shelf-ocean system and its local peculiarities, but it is focused on the common principal characteristics of such systems. For this reason, we consider an idealized configuration based on typical settings of prominent ice shelf regions, especially the Filchner-Ronne Ice Shelf (FRIS). It not only represents the most massive body of floating ice in the world today, but also shows strong ice-ocean interaction leading to the formation of extensive marine ice layers, partly more than $350 \mathrm{~m}$ thick (Thyssen et al., 1992). Furthermore, ISW production in the FRIS area contributes to deep and bottom water formation in the Weddell Sea, which is known as one of the important source regions of Antarctic Bottom Water.

A common limitation of all the former studies is that they do not allow the investigation of the evolution of the coupled ice shelf-ocean system for specified climate scenarios, because no feedbacks between the associated system components are considered. This is only possible with a combined model approach which is introduced in this study.

Hence, Section 2 of this paper first comprises a general description of the basic model components, the ice shelf model and the ocean model, and their coupling. Section 3 then concentrates on the actual model application, including a detailed specification of the model domain characteristics, the chosen initial and boundary conditions, and the adaptation of the model components. Furthermore, the results of our base experiment are presented. Section 3 is closed by discussions on how we simulate tabular iceberg calving and estimate marine ice layer thicknesses. In Section 4, results of sensitivity experiments for three different climate scenarios are shown, which are described with respect to the further evolution of the base experiment. Section 5 comprises a summary and conclusions of the main findings.

\section{The coupled ice shelf-ocean model}

In order to investigate the evolution of a coupled ice shelf-ocean system and its response to changes in climatic boundary conditions, two 3D stand-alone models for ice shelf and ocean are combined to a coupled model approach. Since both climate system components, ice shelf and ocean, have innate timescales for the development of their dynamics, the coupling of established models enables first the simulation of the individual 3D flow regimes. Interactions are then calculated in respect to these results. While sub-ice shelf ocean has overturning timescales of about 10 years (Grosfeld et al., 1997), ice shelf evolution lasts typically for several centuries up to millennia, until a quasi-steady state is reached. However, changes in boundary conditions can impact on much shorter time-scales and considerably influence ice shelf geometry and dynamics (e.g., break-up of northern Larsen Ice Shelf; Vaughan and Doake, 1996).

\subsection{Ice shelf model}

The numerical simulation of ice shelf evolution under prescribed climate boundary conditions is performed with the flow model COMB $I S^{2} \mathrm{~S}$ (Computerbased Ice Shelf/Ice Sheet Simulator; Sandhäger, 2000) in its time-dependent mode. This model captures the characteristics of dynamics and geometry for large ice bodies, including grounded parts (ice sheet regions) as well as adjoining floating portions (ice shelf areas). However, the application of the ice sheet model components (adapted from Blatter, 1995) is confined in our study to small parts of the model domain, where local grounding of the advancing ice shelf on sea floor shoals is computed.

The determination of ice shelf dynamics for a given geometry is based on numerical calculations of an approximate solution of two coupled differential equations, describing the distribution of the horizontal ice velocity. The differential equations are obtained by combining the continuum-mechanical momentum and mass balance equations with Glen's flow law (e.g., Paterson, 1994), the ice shelf approximation (depth-independence of the horizontal velocity component), and the incompressibility condition. With regard to a regular Cartesian $(x, y, z)$-coordinate system, 
these governing equations of ice shelf flow are (e.g., MacAyeal et al., 1986):

$$
\begin{aligned}
& 2 \frac{\partial}{\partial x}\left(F \frac{\partial u}{\partial x}\right)+\frac{\partial}{\partial x}\left(F \frac{\partial v}{\partial y}\right) \\
&+ \frac{1}{2} \frac{\partial}{\partial y}\left(F\left(\frac{\partial u}{\partial y}+\frac{\partial v}{\partial x}\right)\right)=g G_{x} \\
& 2 \frac{\partial}{\partial y}\left(F \frac{\partial v}{\partial y}\right)+\frac{\partial}{\partial y}\left(F \frac{\partial u}{\partial x}\right) \\
& \quad+\frac{1}{2} \frac{\partial}{\partial x}\left(F\left(\frac{\partial u}{\partial y}+\frac{\partial v}{\partial x}\right)\right)=g G_{y}
\end{aligned}
$$

with

$$
F=F(u, v, H, A(T), n) \text { and } G_{x, y}=G_{x, y}(\rho, h, H),
$$

where $\vec{u}=(u, v)$ is the horizontal velocity vector, $H$ the ice thickness, $h$ the ice surface elevation above sea level, $\rho$ the density of the ice body, $g=9.81 \mathrm{~m} \mathrm{~s}^{-2}$ the acceleration due to gravity, and $T$ the ice temperature. The parameters $A(T)$ and $n$ of Glen's flow law are predetermined as follows: the flow factor $A(T)$ as stated by Huybrechts (1992) in accordance with the recommendations of Paterson (1994); the exponent $n=3$. The temperature distribution in the ice body is approximated by means of the simple relation $T(\tilde{z})=\left(T_{\mathrm{s}}-T_{\mathrm{b}}\right)$ $(\tilde{z} / H)^{\frac{1}{3}}+T_{\mathrm{b}}$, where $\tilde{z}$ is the elevation above the ice shelf base, $T_{\mathrm{b}}$ the temperature at the base, and $T_{\mathrm{s}}$ the annual mean surface temperature. This approach disregards, e.g., the special temperature regime of ice shelf areas hosting basal marine ice layers (Grosfeld, 1993), and, therefore, should be replaced by a solution of the heat transfer equation at least for model applications to real ice shelves. The stress conditions within the ice body, i.e., the distributions of the horizontal deviatoric stress components $\tau_{x x}, \tau_{y y}$, and $\tau_{x y}$, are determined from the strain rates (gradients of the velocity field), using Glen's flow law.

The basic equation to calculate the evolution of ice shelf geometry is the vertically integrated mass balance equation, describing the change in ice thickness $H$ with time $t$ (e.g., Paterson, 1994):

$$
\begin{aligned}
\frac{\partial H}{\partial t}= & \frac{\rho_{\mathrm{c}}}{\bar{\rho}}\left(a_{\mathrm{s}}+a_{\mathrm{b}}\right) \\
& -\frac{1}{\bar{\rho}}\left(\frac{\partial}{\partial x}(\bar{\rho} H \bar{u})+\frac{\partial}{\partial y}(\bar{\rho} H \bar{v})\right)-\frac{H}{\bar{\rho}} \frac{\partial \bar{\rho}}{\partial t}
\end{aligned}
$$

where $\bar{u}$ and $\bar{v}$ are the depth-averaged horizontal components of the ice velocity vector, $a_{\mathrm{S}}$ is the surface accumulation rate, $a_{\mathrm{b}}$ the rate of melting/freezing at the ice shelf base, $\rho_{\mathrm{c}}$ the density of completely consolidated ice $\left(\rho_{\mathrm{c}} \approx 915 \mathrm{~kg} \mathrm{~m}^{-3}\right)$ and $\bar{\rho}$ the depth-averaged density of the ice body. Ice shelf thickness evolution is accompanied by surface elevation changes according to hydrostatic equilibrium $h$ $=\left(1-\bar{\rho} / \rho_{\mathrm{w}}\right) H$, where $\rho_{\mathrm{w}}$ is the density of seawater. Grounding of the ice shelf on sea floor shoals of height $h_{\mathrm{f}}$ a.s.l. occurs, if $(h-H)<h_{\mathrm{f}}$. Ice front migration is determined from local ice flux, and the condition that ice front thicknesses always exceed a threshold $H_{\text {min }}$.

The total set of model equations will describe the distributions of the relevant ice dynamic quantities $u$, $v, T, \tau_{x x}, \tau_{y y}$, and $\tau_{x y}$ (subject to the respective ice body geometry), as well as the geometric evolution of the ice body, if the following specifications are added: (1) values for model input and forcing parameters, e.g., for $\vec{u}$ and $H$ at the grounding line, for the mass balance quantities $a_{\mathrm{s}}$ and $a_{\mathrm{b}}$, for $T$ at the surface and bottom of the ice body, and for the critical thickness $H_{\text {min }}$; (2) an equation of state for $\rho$, including a predefinition of $\rho_{\mathrm{w}}$; (3) a boundary condition for the horizontal gradients of $\vec{u}$ at the ice front.

The model grid used for the numerical simulations is composed of block-centered cells. Each cell represents a volume element of ice with a constant base $\Delta x \times \Delta y$ and a height varying with depth level between $0.01 \mathrm{H}$ and $0.2 \mathrm{H}$. The decisive numerical method incorporated into the flow model is a relaxation procedure (e.g., Herterich, 1987) which facilitates to calculate iteratively an approximate solution of the governing equations of ice shelf flow, Eqs. (1) and (2), from their finite-difference forms. The continuity equation for ice thickness, Eq. (3), is implemented into the flow model using the discretized formulation:

$$
\begin{aligned}
H_{i, j}^{r+1}= & H_{i, j}^{r}+\Delta t\left(a_{\mathrm{s} \mid i, j}+a_{\mathrm{b} \mid i, j}\right. \\
& -\frac{\bar{\rho}_{i+1, j}^{r} H_{i+1, j}^{r} \bar{u}_{i+1, j}^{r}-\bar{\rho}_{i-1, j}^{r} H_{i-1, j}^{r} \bar{u}_{i-1, j}^{r}}{2 \rho_{\mathrm{c}} \Delta x} \\
& \left.-\frac{\bar{\rho}_{i, j+1}^{r} H_{i, j+1}^{r} \bar{v}_{i, j+1}^{r}-\bar{\rho}_{i, j-1}^{r} H_{i, j-1}^{r} \bar{v}_{i, j-1}^{r}}{2 \rho_{\mathrm{c}} \Delta y}\right)
\end{aligned}
$$


where $\Delta t$ is the time step, $r$ and $r+1$ denote index numbers associated with simulation times $t$ and $t+\Delta t$, respectively, and $i, j$ are the horizontal grid coordinates. To avoid numerical instabilities, a small dissipation coefficient $D_{i, j}$ is added to the new ice thickness distribution $H^{r+1}$ (cf. Mayer, 1996):

$$
\begin{aligned}
D_{i, j}= & \alpha\left(H_{i-1, j}^{r}+H_{i, j-1}^{r}-4 H_{i, j}^{r}+H_{i+1, j}^{r}\right. \\
& \left.+H_{i, j+1}^{r}\right)+\beta\left(\Delta H_{i-1, j}+\Delta H_{i, j-1}\right. \\
& \left.-4 \Delta H_{i, j}+\Delta H_{i+1, j}+\Delta H_{i, j+1}\right)
\end{aligned}
$$

with $\Delta H=H^{r+1}-H^{r}, \alpha \ll 1$, and $\beta \ll 1$. The maximum time step $\Delta t_{\max }$, enabling a numerically stable simulation of the ice shelf evolution, is given by the appropriate Courant-criterion (e.g., Mayer, 1996). This criterion relates time step to advective velocity and grid resolution.

Although computation of ice shelf geometry evolution by means of Eqs. (4) and (5) includes slight smoothing of each modeled thickness distribution, in most cases spurious ice thickness undulations will develop near the ice shelf front. These undulations are induced by the prescribed thickness gradients at the calving front which are determined with the numerical approach used to simulate ice front advance. Since any conversion from ice free to ice-covered model domain sections (i.e., seaward migration of the calving front) requires extrapolation of the ice thickness pattern into these areas, thickness gradients at the ice front will also change and, possibly, take extreme values. However, these kinds of ice thickness undulations develop as a stable feature of the solution of Eq. (3) and are not a manifestation of numerical instability (Lingle et al., 1991). Since the spurious undulations also take no influence on the general evolution of the ice shelf system, we calculate ice thickness near the ice front without any additional smoothing.

\subsection{Ocean model}

The ocean model used in this study is a version of a three-dimensional ocean general circulation model (Bryan, 1969; Cox, 1984) modified to use generalized vertical $s$-coordinates (Gerdes, 1993). The model is a rigid-lid, hydrostatic primitive equa- tion model, formulated in spherical coordinates. The representation of the vertical plane in $s$-coordinates enables a convenient specification of kinematic boundary conditions, which especially at the ice shelf-ocean boundary follow an inclined surface. The model predicts the horizontal velocity components, potential temperature, and salinity on all $s$ levels. The vertical velocity is computed diagnostically from the continuity equation for an incompressible fluid, and pressure is calculated using the hydrostatic approximation. Density is derived from the nonlinear equation of state in a form given by Mellor (1991). Subgrid-scale processes, except convection, are parameterized using a conventional eddy viscosity-diffusivity formulation with constant coefficients for horizontal mixing of tracers $\left(A_{\mathrm{hh}}=10^{2} \mathrm{~m}^{2} \mathrm{~s}^{-1}\right)$ and momentum $\left(A_{\mathrm{mh}}=6 \times 10^{2} \mathrm{~m}^{2} \mathrm{~s}^{-1}\right)$, and $\left(A_{\mathrm{hv}}=5 \times 10^{-5} \mathrm{~m}^{2} \mathrm{~s}^{-1}\right)$ and $\left(A_{\mathrm{mv}}=10^{-3} \mathrm{~m}^{2} \mathrm{~s}^{-1}\right)$ in the vertical plane, respectively. Model details and special adaptations to subice shelf regimes are given by Determann and Gerdes (1994), Grosfeld et al. (1997), and Gerdes et al. (1999). Beyond this state, a new ice front representation has been implemented, enabling us to consider ice front advance or retreat instead of a fixed position along a constant latitude. This is especially necessary to consider different ice shelf extensions, resulting from coupled model applications.

The ocean model calculates the mass loss of the ice shelf due to basal melting. This process is parameterized according to the three-equation formula described by Holland and Jenkins (1999), which is based on earlier work by Hellmer and Olbers (1989). Since we want to keep the results as simple as possible to focus on the general response of the coupled system rather than to distinguish between different parameterizations, the ocean model is forced by an idealized wind field and a simple thermodynamic sea-ice model for the open ocean. Thus, the model set-up is comparable with experimental configurations used by Grosfeld et al. (1997), who investigate the influence of cavity geometry on the circulation pattern and mass exchange, excluding an ice shelf feedback. The model is initialized with temperature and salinity on all grid points and integrated for about 10 years from an ocean at rest to a quasi-steady state. The time-scale depends on the cavity volume and overturning of the water column, and can be monitored by the mean temperature evolution of each level. 


\subsection{Model coupling}

Ice shelf and ocean interact at their common interface, the ice shelf base. Basal melting or freezing, caused by the oceanic heat flux, lead to ice thickness changes and influence the flow regime of the ice shelf. On the other hand, the ice thickness distribution determines the geometry of the sub-ice shelf cavity. Consequently, changes in the ice shelf draft influence the ocean circulation in two ways: (1) the barotropic flow is steered along $f / H_{\mathrm{w}}$ contours (with $f$ the Coriolis parameter, and $H_{\mathrm{w}}$ the water-column thickness) and, hence, is sensitive to ice thickness; (2) the basal mass exchange as a function of pressure depends on ice shelf draft. Melt and freeze rates as well as ice thicknesses are, therefore, parameters exchanged between both models in a module that handles the interpolation and transformation on the different model grids. While the ocean model is discretized in spherical coordinates, the ice model is solved on a Cartesian stencil.

The coupling module (Fig. 2) comprises two steps. First, the ice shelf draft provided by the initialization and later by the ice shelf model is transferred from Cartesian to spherical coordinates. This quantity represents the upper boundary condition for the ocean and determines in combination with constant bedrock topography the water column thickness. The ocean model is integrated with additional boundary conditions like wind field and surface temperature to a quasi-steady state. The calculated basal melt and freeze rates serve as input for the ice shelf model.
These data are transformed from spherical to Cartesian coordinates and low-pass filtered to avoid smallscale variability, especially near the grounding line where the highest melt rates occur. The ice shelf model is integrated for 50 years. This provides for a sufficiently continuous approach to the steady state of the coupled system. Integrations much longer than 50 years would lead to divergent simulations and, hence, to fluctuations in ice thickness and basal mass balance. Together with boundary conditions for surface accumulation, ice input from inland, and annual mean surface temperature, the given new basal mass balance is used to calculate updated sets for ice shelf dynamics and geometry. These data serve as input for a new 50year coupling cycle.

\section{Base experiment}

\subsection{Configuration of the idealized ice shelf-ocean system}

The initial configuration of the idealized ice shelfocean system is shown in Fig. 3. According to the basic structure of numerous glacial systems, we consider an embayed ice shelf, surrounded by grounded inland ice (ice sheet). The ice shelf dimensions of about $650 \times 550 \mathrm{~km}$ and the basic features of the sea bottom relief correspond roughly to the situation observed in the FRIS region. The location of the grounding line results from the chosen bedrock topography (Fig. 3b), which is given as a U-shaped

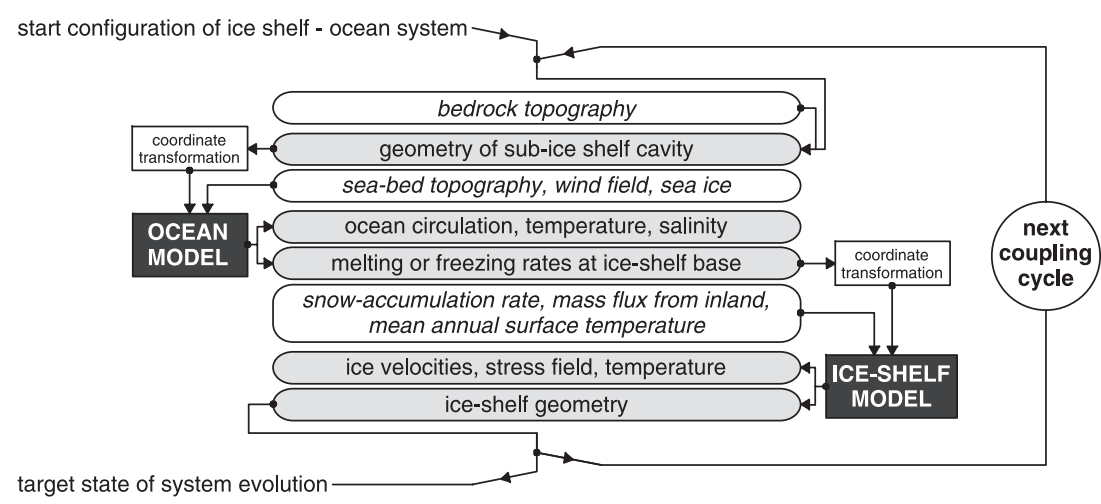

Fig. 2. Flow chart for coupled applications of ice shelf and ocean models. External forcing quantities (white boxes) are prescribed; geometric and inherent dynamical system quantities (gray boxes) are computed repeatedly. Coordinate transformations provide for data set matching between the Cartesian ice shelf model grid and the spherical ocean model grid. 


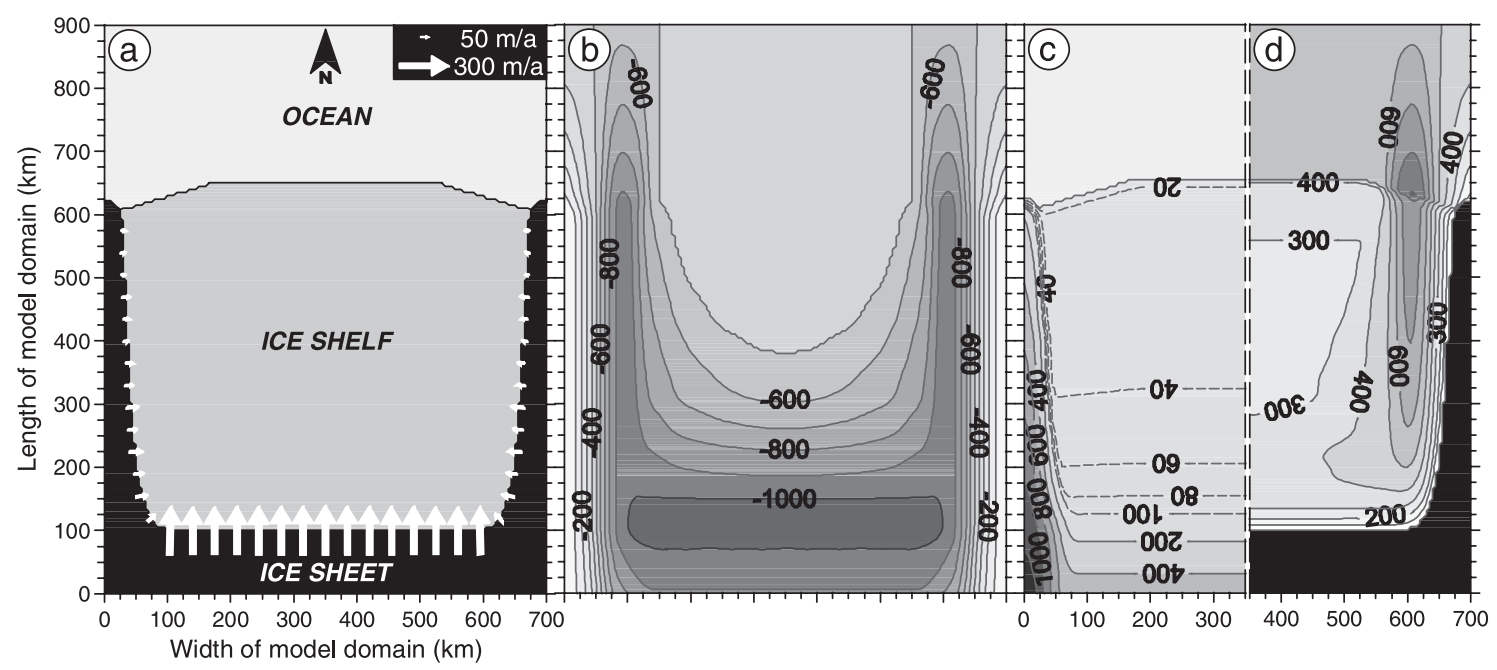

Fig. 3. Initial configuration of the idealized ice shelf-ocean system and predefinition of some essential model input parameters. (a) General structure of the glacial system and prescribed time-invariant velocities of the mass flux over the grounding line; (b) bedrock relief and (c) initial ice surface topography (elevations in m a.s.l.); (d) water column thicknesses (in m). (c) and (d) are zonally symmetric.

depression, partly more than $1000 \mathrm{~m}$ deep, surrounding a shallow central part of about $500 \mathrm{~m}$ depth. The position of the ice shelf front coincides with the interconnection line between the northernmost extensions of the ice sheet (Fig. 3a). The northward adjoining sea floor in the open ocean domain represents an about $500-\mathrm{km}$ wide and flat continental shelf region (cf. Fig. 6c). The transition to the deep sea is not included in our model system.

The initial ice-shelf geometry (Figs. 3c and 5a) has been determined by means of a simple approximation for a uniaxial spreading ice shelf of infinite width (Oerlemans and van der Veen, 1984), and suitable extrapolations into the lateral ice shelf regions. Since any reactions of the ice sheet to changes in ice shelf geometry, ice shelf dynamics, and/or climatic boundary conditions remain unconsidered in our model studies, ice sheet geometry is not relevant here. Ice shelf draft and sea bottom relief define the distribution of water column thickness (Fig. 3d), which amounts in the initial state to maxima of about $760 \mathrm{~m}$ within the sub-ice shelf cavity and $900 \mathrm{~m}$ in the open ocean.

\subsection{Model initialization}

The model studies represented in this paper are confined to simulations of the ice shelf-ocean system. Ice thicknesses at the grounding line and horizontal velocities of steady inland ice discharge are prescribed as fixed time-invariant boundary values for the ice shelf model. Mass flux from inland is concentrated at the southern grounding line section $y=100 \mathrm{~km}(y$ corresponds to the meridional distance of the model domain) and amounts there to $H_{\mathrm{gl}}\left|\vec{u}_{\mathrm{gl}}\right| \approx 1170 \times 290$ $\rho \mathrm{m} \mathrm{year}^{-1}$ (comp. Fig. 3a). Beside areal extent and bedrock relief, the distributions for surface accumulation rate $a_{\mathrm{s}}$ and annual mean surface temperature $T_{\mathrm{s}}$ are chosen according to conditions known for the FRIS (e.g., Morris and Vaughan, 1994):

$$
\begin{aligned}
a_{\mathrm{S}}= & \left(0.3-h \times 3.6 \times 10^{-5} \mathrm{~m}^{-1}-(650 \mathrm{~km}-y)\right. \\
& \left.\times 5.8 \times 10^{-5} \mathrm{~km}^{-1}\right) \frac{\mathrm{m}_{\text {ice }}}{\text { year }} \times\left(1+\left|\frac{\partial h}{\partial s}\right|_{\text {max }} \times 30\right) \\
T_{\mathrm{s}}= & \left(-20-h \times 5.1 \times 10^{-3} \mathrm{~m}^{-1}-(650 \mathrm{~km}-y)\right. \\
& \left.\times 9 \times 10^{-3} \mathrm{~km}^{-1}\right)^{\circ} \mathrm{C}
\end{aligned}
$$

$a_{\mathrm{s}}$ and $T_{\mathrm{s}}$ are varying with surface elevation $h$ and with meridional distance to the ice front $y . a_{\mathrm{s}}$ also depends on the maximum surface slope.

The assumption of a constant temperature at the ice shelf base, $T_{\mathrm{b}}=-2{ }^{\circ} \mathrm{C}$, represents a reliable approximation, although $T_{\mathrm{b}}$ depends on several parameters as 
it represents the freezing point temperature of the adjacent seawater (Foldvik and Kvinge, 1974). The density distribution in the ice body is prescribed by an equation of state for the mean density of the overlaying ice column $\bar{\rho}_{\text {over }}$. For ice column thicknesses, $H_{\text {over }} \geq 100 \mathrm{~m}$, the simple relation $\bar{\rho}_{\text {over }}=\bar{\rho}_{\mathrm{c}}-13463$ $\mathrm{kg} \mathrm{m}^{-2} / H_{\text {over }}$ holds, leading to the hydrostatic relation $h=0.11337 H+13.046 \mathrm{~m}$, if water density is taken as $\rho_{\mathrm{w}}=1032 \mathrm{~kg} \mathrm{~m}^{-3}$. This again is similar to the situation assumed for the FRIS (Thyssen, 1988; Jenkins and Doake, 1991). For $H_{\text {over }}<100 \mathrm{~m}, \bar{\rho}_{\text {over }}$ is calculated by a modified equation, which ensures steadiness at $H_{\text {over }}=100 \mathrm{~m}$ and includes a snow cover density of $370 \mathrm{~kg} \mathrm{~m}^{-3}$ (Fig. 4a). This specification of $\bar{\rho}$ simplifies Eq. (3) for the ice thickness evolution, which can now be calculated independent of temporal density changes.

The ice shelf model considers a boundary condition for the horizontal ice velocity $\vec{u}$ at the calving front, which is based on the balance of forces formulated for an ice edge of idealized rectangular shape (Weertman, 1957). This approach describes the dependency of the horizontal gradients of $\vec{u}$ at the ice front on freeboard $h$, ice thickness $H$, and density distribution $\rho . H$ is directly associated with $h$ by the hydrostatic relation (Fig. 4b). Assuming a constant ice density $\rho=\rho_{\mathrm{c}}$ and defining a reduced equivalent freeboard $h_{\text {equi }}$ leads to a more concise formulation of this boundary condition. In case the ice shelf flow takes place in $x$-direction perpendicular to the ice front, the condition reads:

$\frac{\partial u}{\partial x}=\frac{H \rho_{\mathrm{c}} g h_{\text {equi }}}{4 F}-\frac{1}{2} \frac{\partial v}{\partial y} ; \frac{\partial v}{\partial x}=-\frac{\partial u}{\partial y}$

with $F$ from Eqs. (1) and (2).

Compared to observed ice front characteristics, Eq. (8) mostly overestimates the velocity gradients, because the used approach of the rectangular shape describes an unrealistically high freeboard. Measurements of the FRIS ice front geometry (Thyssen, 1988) show a pronounced seaward thinning, which is a typical feature of numerous ice shelves and caused by locally increased erosion due to tidal and wind activities. The impact of this reduced effective freeboard on the ice shelf flow is simulated by substituting $h_{\text {equi }}$ in Eq. (8) by an effective freeboard $h_{\text {eff. }}$.

Fig. 4b shows the chosen correlation between $h_{\text {eff }}$ and ice front thickness $H$, with a critical threshold required to simulate ice front migration at $H_{\min }=200$ $\mathrm{m}$. The relation $h_{\mathrm{eff}}(H)$ is based on the following assumptions: (1) close to the ice front increased ice shelf erosion occurs $\left(h_{\text {eff }}<h_{\text {equi }}\right)$; (2) the maximum freeboard is constrained, following stability arguments ( $h_{\mathrm{eff}} \approx 31 \mathrm{~m}$ for $H>400 \mathrm{~m}$ ); (3) moderate ice thickness changes have no effect, if the ice front thickness hardly exceeds its critical value $H_{\text {min }}$ ( $h_{\text {eff }}=10 \mathrm{~m}$ for $H \leq 250 \mathrm{~m}$ ); (4) for the ice thickness
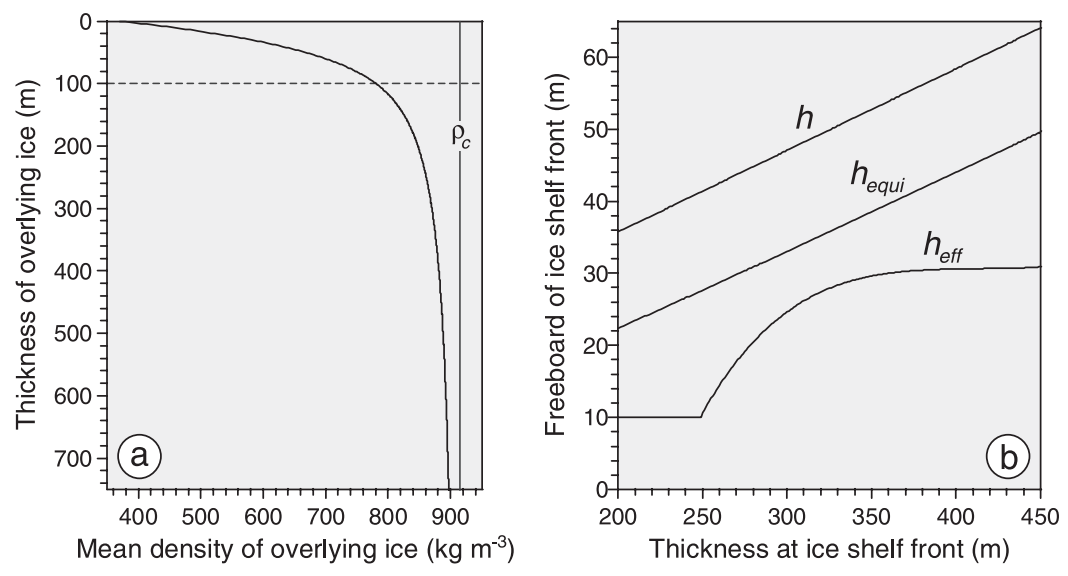

Fig. 4. Prescribed ice shelf model input relations (a) between mean density $\bar{\rho}_{\text {over }}$ and thickness $H_{\text {over }}$ of the overlaying ice column and (b) between effective freeboard $h_{\text {eff }}$ and ice thickness $H$ as considered for the ice front boundary condition. (b) additionally shows freeboard $h$ as calculated from the hydrostatic relation and equivalent freeboard $h_{\text {equi }}$, compensating for the simplification $\rho=\rho_{\mathrm{c}}$ in the boundary condition. 
interval from about 275 to $375 \mathrm{~m}$, the difference between $h_{\text {equi }}$ and $h_{\text {eff }}$ is relatively small, because otherwise a simulation of calving events would result in unrealistic large changes in ice dynamics of the 'post-calving' vs. 'pre-calving' state.

Furthermore, a contribution $a_{\mathrm{b} \mid \text { front }}$ to the basal mass balance is added to consider the widely observed enhancement of ice front melting due to tides and the seasonally warmer waters of the coastal current (Jacobs et al., 1985) up to a distance $\tilde{s}$ from the ice front $(\tilde{s}=0)$ :

$a_{\mathrm{b} \mid \text { front }}=-2 \mathrm{~m}_{\text {ice }}$ year $^{-1} \times 0.5^{0.5 \tilde{s} \mathrm{~km}^{-1}}$

for $\tilde{s}<25 \mathrm{~km}$.

While the horizontal model grid resolution is constant, $\Delta x \times \Delta y=5 \times 5 \mathrm{~km}$, the temporal resolution is optimized for each phase of the ice shelf evolution modeling. The time-step $\Delta t$ varies between 1.2 and 5.1 years with a mean value of 2.2 years.

Keeping with the idealized nature, of the model configuration the ocean model is initialized with constant temperature at surface freezing point $\left(T_{\mathrm{f}}\right.$ $=-1.9{ }^{\circ} \mathrm{C}$ ) over the whole grid and salinity of $34.6-34.67$ from top to bottom. The ocean surface is restored to $T_{\mathrm{f}}$ and forced by a simple 1D-thermodynamic sea ice model (Grosfeld et al., 1997) and a wind stress field that is zonally invariant, but varies sinusoidally with latitude. The wind stress changes from a minimum of $-0.05 \mathrm{~Pa}$ (westward) at the southern boundary of the open ocean (the ice shelf front) to a maximum of $0.05 \mathrm{~Pa}$ (eastward) at the northern boundary. The wind forcing induces a cyclonic ocean circulation as is the case for the Weddell Sea sector off the Filchner-Ronne Ice Shelf. For the present study, the model comprises 10 vertical $s$-layers in the ice shelf cavity, with thicknesses varying from about $2 \%$ of water column thickness in the top layer, to about $23 \%$ of the water column thickness in the bottom layer. In the open ocean, four additional upper levels have constant thicknesses, each a quarter of the ice front draft which is set to a constant value. The horizontal resolution of the model domain is $0.1^{\circ}$ meridionally and $0.3^{\circ}$ zonally, which corresponds, respectively, to $11 \mathrm{~km}$ and about 5 to $10 \mathrm{~km}$ grid distances, depending on latitude.
As stated above, the ocean is restarted for each coupling cycle with the new ice shelf draft calculated by the ice shelf model. Therefore, the tracer initialization for temperature and salinity starts for subsequent model runs where the last step finished. Only velocities are set to zero, but recover within short time scales due to the given density field and corresponding pressure gradients. Along the northern closed boundary, a restoring zone of five-grid cells $\left(0.5^{\circ}\right)$ is defined where temperature and salinity are damped to the given initialization, using a Newtonian damping scheme with a time scale of 25 days. This procedure compensates for the permanent cooling due to glacial freshwater input by melting at the ice shelf base and the impact of recirculation along the closed boundary. For later climate scenario simulations, this boundary condition is altered.

\subsection{System evolution from initial to transient 300- year states}

The base experiment comprises six cycles of the coupled application of the ice shelf and ocean models. The following results show the evolution of the ice shelf-ocean system over a period of 300 years from the initial configuration to a transient stage. In contrast to the non-uniform rapid system evolution during the first about 100 years (spin-up phase), the 300-year stage depicts a largely convergent moderate evolution toward a quasi-steady state for the given boundary conditions (cf. Fig. 10).

The overall evolution of the ice shelf-ocean system up to the 300-year stage is characterized by significant changes of ice shelf geometry and dynamics, accompanied by a general change in the ocean flow of the sub-ice shelf cavity. Hence, conspicuous changes in the distribution of the basal melt and freeze rates occur, emphasizing the major importance of this quantity for the coupled ice shelf-ocean system.

In Fig. 5a-c, ice thickness distributions for 0 , 150, and 300 years are displayed. Compared to the initial configuration (Fig. 5a), the ice thickness evolution is characterized by a rapid thinning close to the southern grounding line. In most other ice shelf regions, a moderate continuous ice thickening occurs and, simultaneously, the ice thickness pattern becomes more and more differentiated with time. Enhanced basal melting related to the eastern oceanic 


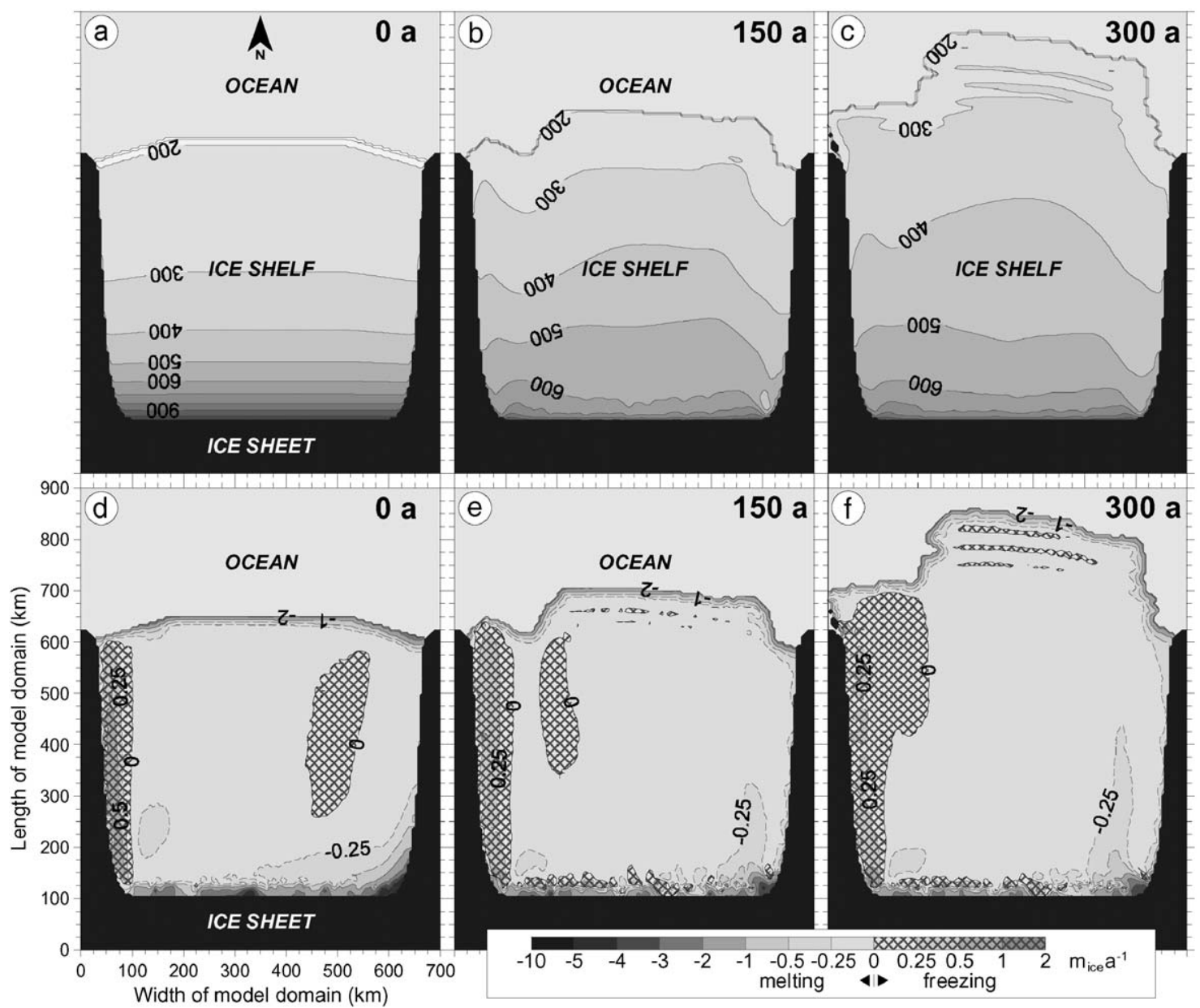

Fig. 5. (a) Initially prescribed ice shelf thicknesses (in $\mathrm{m}$ ) and (b, c) thickness distributions after 150 and 300 years of simulated system evolution, respectively; (d) to ( $\mathrm{f}$ ) associated mass balances (in $\mathrm{m}_{\mathrm{ice}}$ year ${ }^{-1}$ ) at the ice shelf base, where melting processes dominate, but accumulation of marine ice also occurs (hatched areas). The simulation results indicate substantial ice front advance as well as local ice shelf grounding on sea floor shoals off the furthest northwestern ice sheet region. Elongated zones of locally increased basal melting and freezing near the calving front coincide with spurious ice thickness undulations, originating from the approach used to simulate ice front advance.

inflow (Fig. 5d-f) causes a significant thinning of the ice shelf, whereas sustained accumulation of marine ice related to the western outflow leads to comparatively larger ice thicknesses. Furthermore, the thickening of the central and northern ice shelf parts causes a successive ice front advance of about 210 $\mathrm{km}$ in 300 years, involving a coverage of large parts of the open ocean. The occurrence of the distinct ice front asymmetry in the 300-year stage represents a plausible feature imposed by our numerical approach to compute ice front migration. In the northeastern ice shelf region, basal melting provides for a rapid thinning of advanced ice shelf sections down to the chosen threshold thickness $H_{\min }=200 \mathrm{~m}$ and, hence, entails the loss of these sections. Similar small-scale fluctuations in ice front position are reported from regions where the continuous seaward ice shelf flux is compensated by frequent calving of small icebergs and/or heavy melting. In contrast to that, the thicknesses of the ice shelf portion advancing in the northwest are largely kept above $H_{\text {min }}$ because of the predominance of basal freezing there. Thus, giant tabular iceberg calving can be addressed as the principal process for ice front retreat in both the western 
ice shelf region and the central part, where ice front advance rates are largest due to highest seaward ice fluxes (cf. Fig. 7). Obviously, the occurrence of the elongated zones of marine ice accumulation near the ice front is correlated directly with the expected development of spurious ice thickness undulations in this area (see Section 2.1) and, hence, does not represent a genuine feature of ice shelf-ocean system evolution. In contrast to that, the zones of strong melting (between 2 and $10 \mathrm{~m}_{\text {ice }}$ year $^{-1}$ ) and local freezing (partly exceeding $1 \mathrm{~m}_{\text {ice }}$ year $^{-1}$ ) near the southern grounding line are induced by the large gradients of the ice shelf draft, causing super-cooling of meltwater within short distances and subsequent formation of marine ice at shallower depth.

Fig. $5 \mathrm{~d}-\mathrm{f}$ shows a general change in the basal melt and freeze pattern as a direct consequence of an ocean circulation reversal in the central ice shelf cavity during the spin-up phase of the base experiment (Fig. 6). According to Grosfeld et al. (1997), the circulation in ice shelf cavities is dominated by the barotropic flow. Due to the weak stratification of the ocean, the circulation is steered along contours of constant $f / H_{\mathrm{w}}$ and, therefore, is highly sensitive to changes in water column thickness. These are determined by the ice thickness evolution during the first 300 years. The ocean regime reacts such that the initial anticyclonic flow over the shallow central plateau and cyclonic flow within the deep western and eastern troughs (Fig. 6a) change to a uniform cyclonic flow pattern over the whole model domain (Fig. 6b). Accordingly, the initial phase is characterized by temporary accumulation of marine ice in the eastern central part of the cavity, where outflowing super-cooled water rises along the ascending ice shelf base. After the adjustment to the new cavity shape, flow regime changes (cf. Figs. 3d and 6c) with inflow concentrated along the eastern grounding line and outflow only along the western boundary. Hence, basal freezing is limited to the western ice shelf (Fig. 5e,f).

The simulated ice front advance reduces the open ocean area exposed to the wind, leading to reduced gyre flow and transports. However, this has no general consequences for the ventilation of the ice shelf cavity. As shown by Grosfeld et al. (1997), the ice shelf front represents a dynamic barrier for barotropic flow. Therefore, changes in open ocean circulation

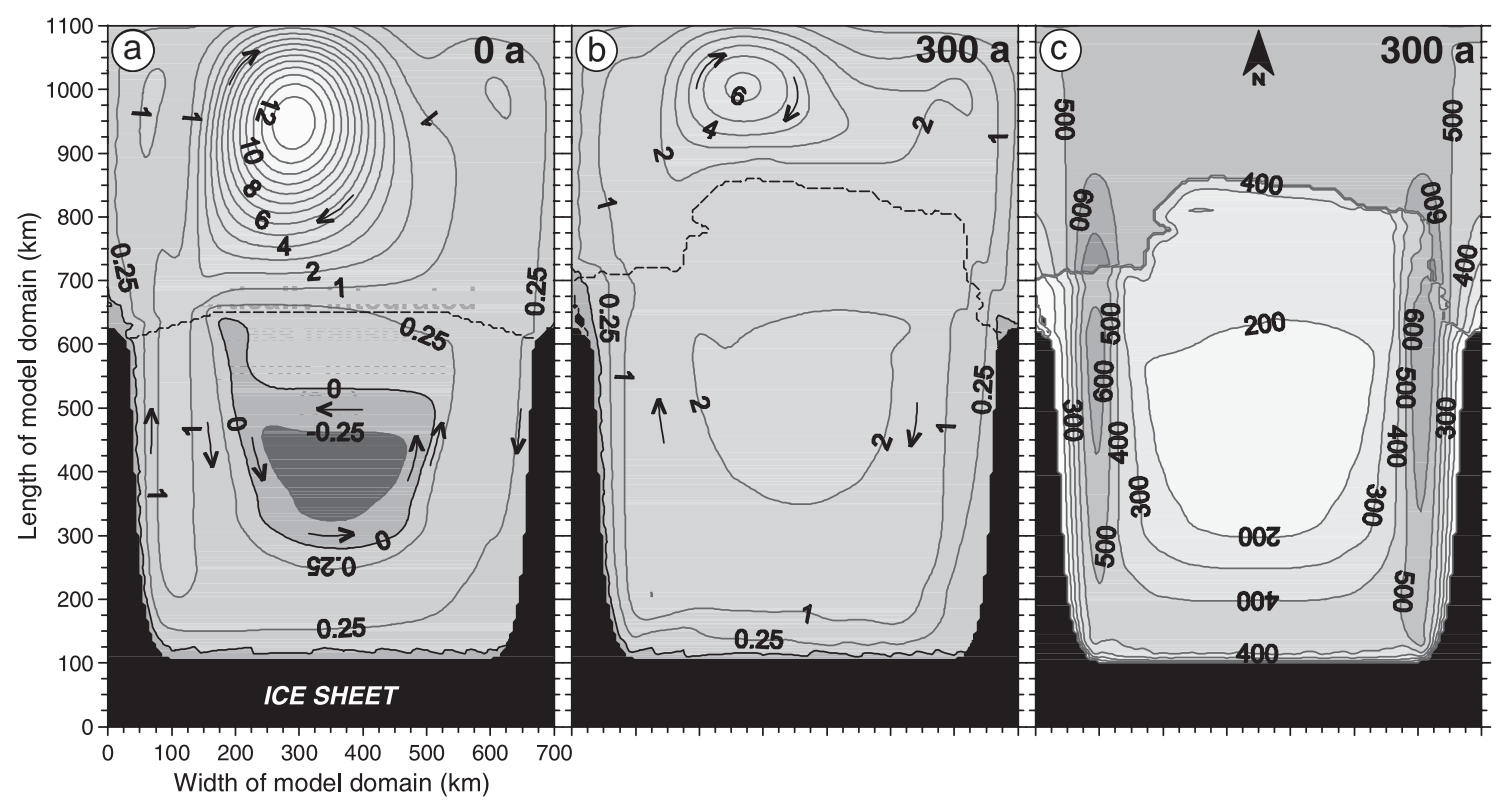

Fig. 6. (a, b) Modeled distributions of the vertically integrated mass transport stream function (in Sv) for the initial and 300-year states of the idealized ice shelf-ocean system, respectively. Negative values indicate anticyclonic flow, positive values cyclonic circulation (cf. arrows). (c) Map of water column thickness (in m) after 300 years of simulation time. 
have no direct impact on the ice shelf cavity flow. Here, an independent circulation regime establishes, controlled by the given geometry and the freshwater flux resulting from ice-ocean interactions.

The modeled horizontal ice velocity fields for 0 , 150, and 300 years are displayed in Fig. 7. Despite the simplified initial ice body geometry, the simulated ice dynamics reflect a typically structured ice shelf flow regime already at this stage. Low velocities are found along western and eastern grounding zones, where the mass flux from inland is small, whereas high velocities occur off the southern 'active' grounding line, with maximum values close to the central ice shelf front.

The rapid ice shelf thinning near the southern grounding line during the first 50 years leads to a strong reduction of ice velocities while flow almost does not change directions. For the same reason, mean ice velocities as well as maximum values near the ice front decrease, the latter from more than 1800 to about $1200 \mathrm{~m} \mathrm{year}^{-1}$ within the first 50 -year cycle. Thereafter, the ice dynamics experiences only moderate changes, as indicated, e.g., by the alterations in ice shelf kinetic energy (Fig. 10c). The continuous ice front advance causes again an increase in ice front velocities (Fig. 7b,c), because of the almost unresisted ice shelf spreading beyond a limit of lateral compression.

\subsection{Simulation of ice front retreat due to tabular iceberg calving}

The base experiment shows that the simulated evolution of the ice shelf-ocean system involves substantial ice front advance. Since large-scale unresisted ice shelf spreading represents a potentially unstable situation, a straight continuation of the experiment would force the model system to pass through increasingly unrealistic evolution stages. In addition, persistent ice front advance would minimize the remaining open ocean area and, therefore, would cause unacceptable changes of both, the ocean model boundary conditions and the basic experimental specifications.

Thus, to obtain reliable results for the system evolution beyond its 300-year state, ice front retreat due to tabular iceberg calving is imposed. This improves the consistency between modeled and observed ice shelf behavior, because any (stable) ice shelf is subject to more or less periodical alternations of steady ice front advance and sudden retreat due to iceberg break offs. In the long-term mean, this characteristic cycle ensures nearly constant ice shelf extent. Associated mean ice front positions usually coincide with interconnection lines between the furthest seaward pinning points

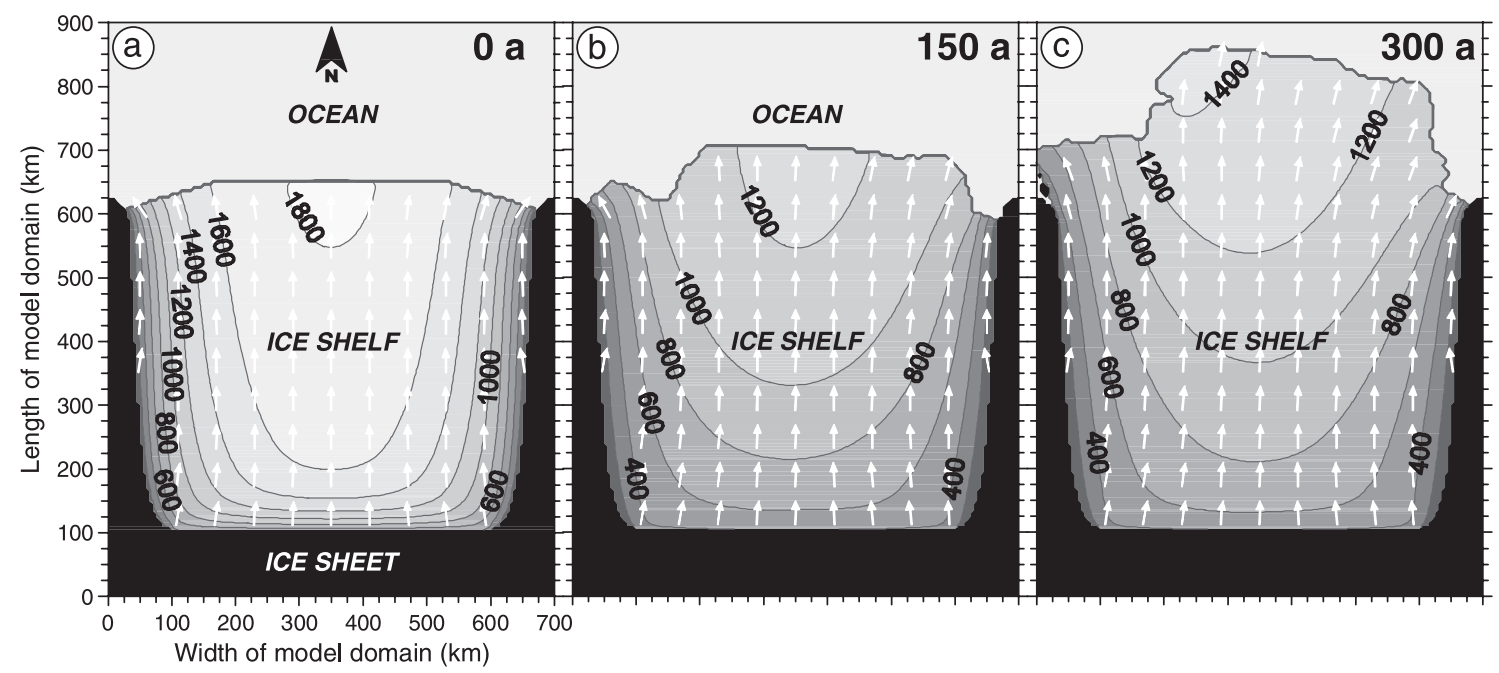

Fig. 7. Modeled distributions of horizontal ice shelf velocity (a) for the initial ice body geometry and (b, c) for the geometrical characteristics after 150 and 300 years of simulated glacial evolution, respectively. Magnitudes (in $\mathrm{m}$ year ${ }^{-1}$ ) of ice velocity vectors are depicted by contours; flow directions are indicated by arrows. 
(e.g., prominent inlands, ice rises, and ice rumples) of the respective ice shelf.

The basic mechanisms of tabular iceberg calving are as yet largely unclear. However, there is observational evidence that calving is usually initiated by formation and growth of inlets, penetrating the edge of the advancing ice shelf. While this initial phase lasts for several years up to decades, final iceberg break off is caused by abrupt crack propagation mostly from one inlet tip either to another one or to a distant point at the ice front. Apparently, the final fracturing tends to advance along pre-existing zones of weakness within the ice body (e.g., rifts), which represent elongated anomalies in ice shelf geometry and dynamics.

Although ice shelf modeling is performed here without consideration of fracture processes and frac- ture-induced effects on the ice body characteristics, the simulated stress field near the ice shelf front comprises significant anomalies in the distribution of the second principal horizontal deviatoric stress $\tau_{2}$ (Fig. 8a). The two principal stresses $\tau_{1}$ and $\tau_{2}\left(\tau_{1} \geq \tau_{2}\right)$ are obtained by expressing the stress components $\tau_{x x}, \tau_{y y}$, and $\tau_{x y}$ with respect to the principal axes instead of the arbitrarily defined $x$ - and $y$-axes of the model domain. A comparison of Figs. $5 \mathrm{c}$ and $8 \mathrm{a}$ shows that the weaker anomalies of locally increased dilatation $\left(\tau_{2}>0\right)$, which occur in the northernmost ice shelf section, are directly connected with the spurious thickness oscillations, originating from the numerical approach used to simulate ice front advance. The southern and most distinct anomaly in the $\tau_{2}$ distribution, however, does not coincide with such an ice thickness undulation. This
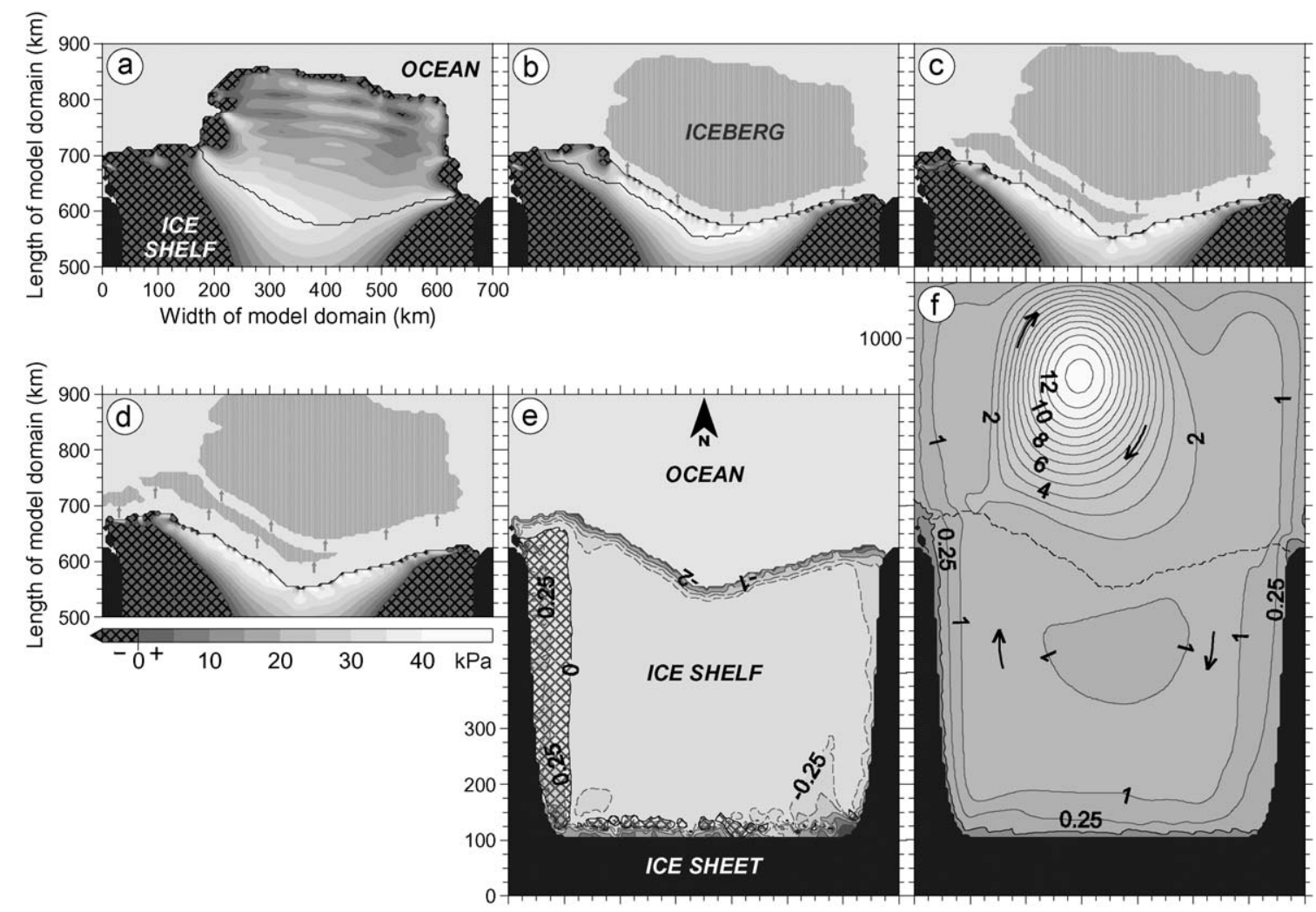

Fig. 8. Simulation of ice front retreat due to successive calving of three tabular icebergs covering a total area of $107,225 \mathrm{~km}^{2}$. (a) $-(\mathrm{d})$ Transition from the 'pre-calving' configuration to the 'post-calving' stage and associated distributions of the second principal horizontal deviatoric stress $\tau_{2}$ (cross-hatching indicates ice shelf areas where $\tau_{2}$ is negative and describes compression). Calving is parameterized with respect to positive (dilative) anomalies of $\tau_{2}$. Dynamics of tabular icebergs and their impact on the oceanic circulation regime are neglected. (e) Basal mass balance (in $\mathrm{m}_{\text {ice }}$ year $^{-1}$ ) and (f) vertically integrated mass transport stream function of the ocean (in Sv) for the 'post-calving' stage as simulated by the ocean model. 
anomaly, extending over about $530 \mathrm{~km}$ from one prominent ice front embayment to a second one ('inlets'?), therefore relates to the large-scale ice shelf geometry and dynamics. Since a calving-induced ice shelf retreat up to the inland bay opening can be expected, the identified distinct stress anomaly seems to be appropriate to establish a plausible 'post-calving' ice front position. This assumption is supported by two additional indications. First, the stress component $\tau_{2}$ is closely connected with horizontal principal strain rates on which analyses of ice shelf stability are based (Doake et al., 1998). The existence of such an intercorrelation between ice shelf stability and its calving characteristics is also evident from observations particularly of different stages of recent ice shelf disintegrations around the Antarctic Peninsula. Second, the model results for the early states of simulated ice shelf evolution suggest that the distinct anomaly in the $\tau_{2}$ distribution is already completely developed after about 80 years of simulation time at a mean meridional distance from the ice front of less than $100 \mathrm{~km}$. Values of the same order of magnitude are stated for the periodicity of major calving events and giant Antarctic iceberg dimensions, respectively. Hence, our hypothesis used for modeling calving events is that pronounced elongated anomalies in the inherent $\tau_{2}$ stress field can be directly assigned to future ice shelf front positions (Fig. 8a,b). Since calving dates are induced in this study only from the requirement to recover the open ocean domain (instead of considering the development of the stress anomaly), both calving cycle periodicities (300 years) and resulting icebergs extensions (up to about $400 \times 250 \mathrm{~km}$; Fig. 8b) are unrealistically large here.

The new ice front configuration is characterized by an altered shape and larger ice thicknesses which, in turn, correspond to higher effective freeboards in the ice shelf model boundary condition (cf. Fig. 4b). Thus, an additional (diagnostic) model run is performed to adjust ice shelf dynamics for the new ice body geometry. The resulting distribution of second principal stress shows again by an elongated positive anomaly (Fig. 8b), used to describe a second iceberg break off (Fig. 8c). A third calving finally yields a comparatively small tabular iceberg at the western ice shelf front (Fig. 8d), before the re-updated flow model results show no further crucial anomaly in the second principal stress field (Fig. 8d).
Despite the lack of detailed quantitative insights, it can be inferred particularly from the high consistency of multi-date ice velocity measurements (e.g., Vaughan and Jonas, 1996) that tabular iceberg break offs from a stable ice shelf barely influence the overall flow regime. In accordance with this, the simulated calving event for the idealized glacial system entails only small changes in ice shelf dynamics. For instance, the kinetic energy of the ice body part south of $y=500 \mathrm{~km}$ reduces by less than $4 \%$ (cf. Fig. 10c). On the other hand, the calving-induced enlargement of the open ocean area leads to a substantial increase in maximum gyre intensity from about $6 \mathrm{~Sv}$ to more than $12 \mathrm{~Sv}$ (cf. Fig. $8 \mathrm{f}$ with Fig. 6b), so that the simulated open ocean conditions for the 300-year 'post-calving' state are almost identical with the initial configuration of the model system (cf. Fig. 8f with Fig. 6a). Regarding the ice shelf cavity, the transition from 'pre-calving' to 'post-calving' states is accompanied by only minor reductions of the cyclonic flow (cf. Fig. 8f with Fig. 6b) and the mean intensity of mass exchange at the ice shelf base (cf. Fig. 8e with Fig. 5f; cf. also Fig. 10d,e). The general pattern of the basal mass balance as well as the structure of the ocean circulation remains almost unaffected by the simulated ice front retreat.

The 300-year 'post-calving' configuration of the ice shelf-ocean system can, therefore, be used as a new geometric setup for a reliable continuation of the base experiment. All tabular icebergs, resulting from the successive application of the calving criterion, are removed, because further iceberg evolution and iceberg-induced effects on the ocean (e.g., by iceberg grounding and/or melting) are not considered in our model.

\subsection{Determination of basal marine ice layer thickness}

The results of the base experiment reveal that mass exchange between ice shelf and ocean is mainly governed by melting at the ice shelf base (Fig. 5d-f). Since basal melting causes ice body erosion and cold freshwater supply to the ocean boundary layer, the associated mass flux is directed from the ice shelf toward the ocean. A reversed basal mass flux, as prevailing for the western ice shelf region, corresponds to marine ice formation. This process comprises crystallization of ice platelets in the water column, subsequent buoyant agglomeration 
at the ice shelf base, and final consolidation of these platelets. Thus, persistent basal accumulation can cause the formation of large consolidated marine ice bodies beneath the meteoric ice (formed by snow accumulation) as found, e.g., underneath the FRIS (Thyssen, 1988). The largest marine ice body covers an area of about $85,000 \mathrm{~km}^{2}$, and is partly more than $350 \mathrm{~m}$ thick (Thyssen et al., 1992). Its typical elongated shape results from continuous advection of the marine ice with the ice shelf flow. Neither in the ice shelf model nor in the ocean model the process of marine ice formation is considered in this complex form. Up to now, only Jenkins and Bombosch (1995) made an attempt to model the process of marine ice formation by accumulation of frazil ice crystals. Their 1Dplume model along a prescribed flowline with given ice shelf draft considers the suspension and deposition of ice crystals of constant diameter, but calculates the accumulation rate at the ice shelf base as solid ice. This neglects the formation of a so called 'slush-layer' where consolidation of frazil ice crystals to solid ice and the detrainment of brine occur. In our ocean model, the process of basal freezing is parameterized in the way of reversed melting, where the amount of in situ super-cooling provides a heat flux away from the ice-ocean interface and determines the basal freeze rate. This concept also neglects the slush-layer and results in a freeze rate for completely consolidated ice.

In order to estimate the marine ice layer geometry for the ice shelf component of our model system, the thickness evolution of marine ice is determined on the basis of the vertically integrated mass balance Eq. (3) and associated numerical conversions Eq. (4) and Eq. (5). Assuming that the marine ice is completely consolidated $\left(\rho_{\mathrm{mar}}=\rho_{\mathrm{c}}\right)$ and the depth-averaged horizontal ice shelf velocities $\bar{u}$ and $\bar{v}$ do not depend on the respective local thickness ratio between marine and meteoric ice, Eq. (3) turns to:

$\frac{\partial H_{\mathrm{mar}}}{\partial t}=a_{\mathrm{b}}-\left(\frac{\partial}{\partial x}\left(H_{\mathrm{mar}} \bar{u}\right)+\frac{\partial}{\partial y}\left(H_{\mathrm{mar}} \bar{v}\right)\right)$

where $H_{\mathrm{mar}}$ is the marine ice layer thickness and $a_{\mathrm{b}}$ the basal mass balance of the ice shelf. Starting from the initial condition $H_{\mathrm{mar}}(t=0)=0 \mathrm{~m}$, an approximate solution for the evolution $H_{\text {mar }}(t)$ over the period $0<t \leq 300$ years can be determined directly from $\bar{u}, \bar{v}$, and $a_{\mathrm{b}}$ of the base experiment. Since marine ice layers cannot have negative thicknesses, Eq. (10) is solved subject to the constraint $H_{\mathrm{mar}} \geq 0$. In the strict sense, however, $H_{\mathrm{mar}}$ represents an 'equivalent' marine ice thickness (cf., Grosfeld et al., 1998). While measured thickness data usually consider both the upper consolidated marine ice and the lower slush-layer, modeled $H_{\text {mar }}$ corresponds to a thickness of a single homogeneous layer causing the same buoyancy than the composition of solid and unconsolidated marine ice.

Fig. 9 shows the estimated thickness distributions of marine ice for the 150- and 300-year states of the idealized model system. At the western margin, persistent basal accumulation (cf. Fig. 5d-f) forms a comparatively large marine ice body with maximum thicknesses of about $80 \mathrm{~m}$ and a total volume of about $2200 \mathrm{~km}^{3}$ after 300 years of simulation. Basal accumulation computed for the eastern central part of the ice shelf region (Fig. 5d) produces only temporarily a distinct marine ice body. Its maximum extent and thickness $(>20 \mathrm{~m})$ occur after about 150 years of simulation, before the change in ocean circulation induces a transition to basal melting (cf. Figs. 5d,e and $6 \mathrm{a}, \mathrm{b}$ ), followed by successive basal erosion. The remnant of this marine ice body is advected by the ice shelf flow and, therefore, located north of its formation area after 300 years.

Similar to the overall development of the ice shelf-ocean system, the evolution of marine ice thickness has merely reached a transient but not yet a (quasi-)steady state after 300 years. Regarding the ice shelf part located south of $500 \mathrm{~km}$ meridional distance, the annual increase of marine ice still amounts to about $2.8 \mathrm{Gt}$, while the total mass gain, i.e., the mass balance excess for this portion, is about $19 \mathrm{Gt} \mathrm{year}^{-1}$ (cf. Fig. 10a,b).

\section{Climate sensitivity experiments}

\subsection{System evolutions from 300- to 1000-year states}

To investigate the response of the coupled ice shelf-ocean system to changes in the climatic boundary conditions, we chose three different scenarios. One considers an atmospheric impact on the ice shelf due to increased surface accumulation rates, and two address the impact of ocean warming. The degree of 


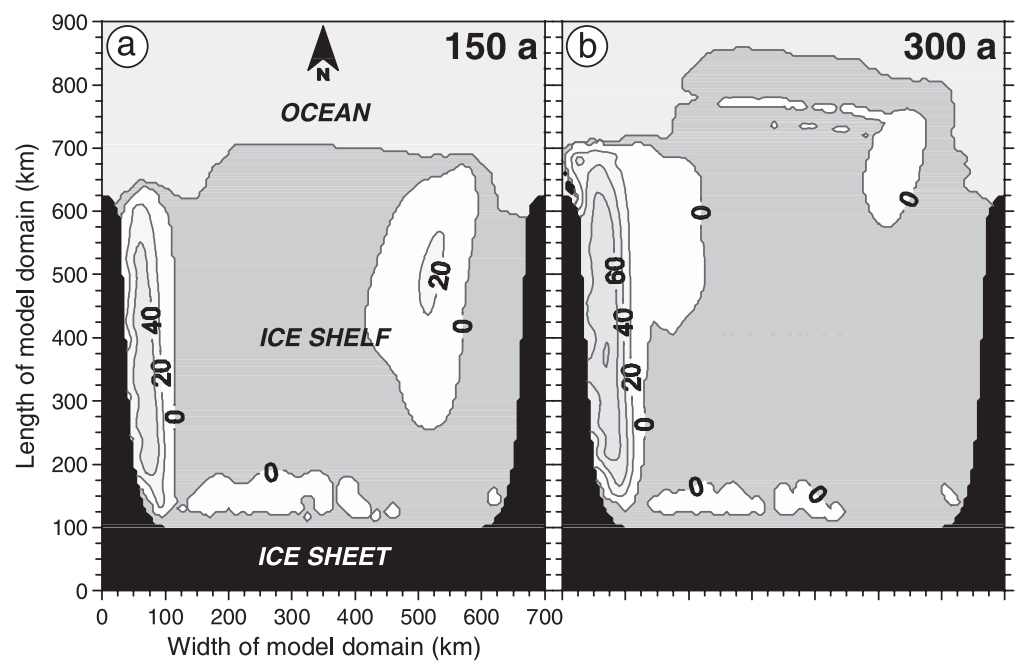

Fig. 9. Simulated marine ice thicknesses (in m) (a) after 150 years and (b) after 300 years of ice shelf evolution, starting from no marine ice. The marine ice body is assumed to be completely consolidated.

change in the climatic boundary conditions for our simulations is motivated by modeling studies of various climate change scenarios. Manabe and Stouffer (1994) discuss the effects of a gradual increase of atmospheric $\mathrm{CO}_{2}$ concentration on precipitation and ocean temperature. Similar to that, O'Farrell et al. (1997) simulate the impact of increasing atmospheric $\mathrm{CO}_{2}$ on accumulation and mass balance of the Antarctic Ice Sheet. Their study is based on results of the climate scenario modeling efforts in the framework of the Intergovernmental Panel on Climate Change (IPPC) greenhouse scenarios (Leggett et al., 1992).

Both studies predict an atmospheric warming as response to a $\mathrm{CO}_{2}$ increase. However, the rate of predicted temperature rise depends on the chosen scenario. Between double and four times the present $\mathrm{CO}_{2}$ concentration the ocean temperature, e.g., in the Weddell Sea would increase by about 1 to $2.5{ }^{\circ} \mathrm{C}$ between 250 and $750 \mathrm{~m}$ depth. Above, cooling occurs as a result of increased precipitation and sea ice melting (O'Farrell et al., 1997). The water, entering the shallow continental shelf of the southern Weddell Sea with the capability to flood the ice shelf cavities is additionally modified by sea ice formation. Surface waters at the freezing point are mixed down due to their higher salinity (cf. Fig. 1). However, sea ice formation is not comparable to the present day rate, and a stronger stratification of the water column is expected in a warming climate. Hence, spreading of warmer circumpolar surface and deep waters onto the continental shelf and further into the ice shelf cavities is hard to predict. On the other hand, atmospheric warming will similarly increase precipitation over Antarctica, because of the air containing more moisture (Warrick et al., 1995). Thus, surface accumulation over ice shelves might increase from only $10 \%$ at the continental margins up to more than $100 \%$ according to the chosen scenario (Manabe and Stouffer, 1994; Budd et al., 1994; O’Farrell et al., 1997).

For our investigation of the climate response of the coupled ice shelf-ocean system to climate warming, we defined three scenarios:

II: doubled surface accumulation rate,

III: moderate ocean warming of $0.2{ }^{\circ} \mathrm{C}$, and

IV: strong ocean warming of $0.5{ }^{\circ} \mathrm{C}$ over the full water column.

For comparison, the base experiment is continued as scenario I. The model experiments for the climate scenarios all cover the same simulation period from 300 to 1000 years, with two (three) tabular iceberg calving events in year 600, 800 (only for scenario II), and 900, respectively. Admittedly, the time intervals chosen between two calving events disregard ob- 

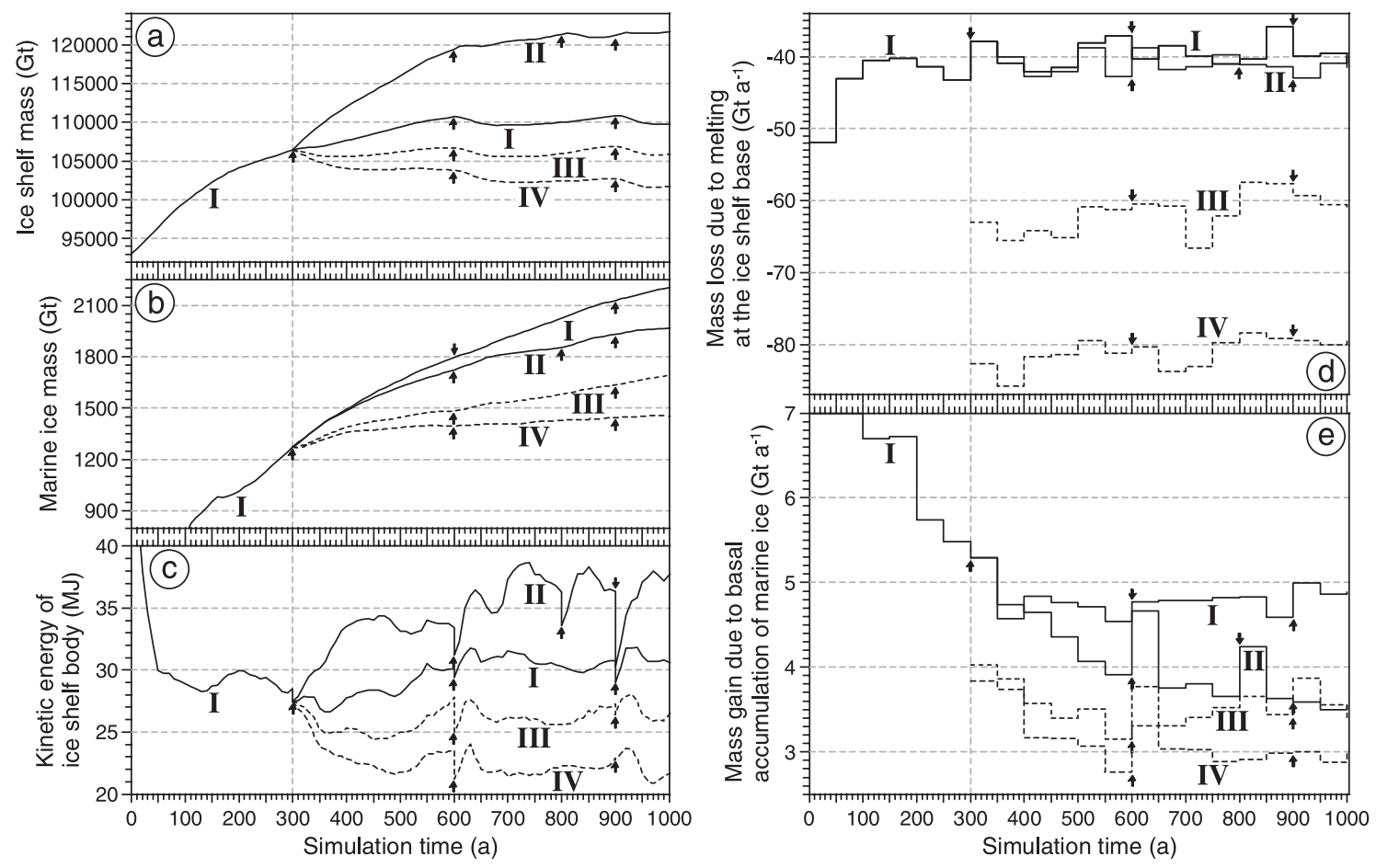

Fig. 10. Convergence diagrams for the evolutions of the coupled ice shelf-ocean system, as simulated in the base experiment I, scenario II (doubled surface accumulation rate), III (moderate ocean warming), and IV (strong ocean warming): (a) total ice mass (in Gt), (b) marine ice mass (in Gt), (c) total kinetic energy (in MJ) of the ice shelf body, (d) mass loss due to melting at the ice shelf base (in Gt year ${ }^{-1}$ ), (e) mass gain due to freezing at the ice shelf base (in Gt year ${ }^{-1}$ ). Arrows indicate dates of imposed iceberg calving events. All quantities refer to the model domain part between 100 and $500 \mathrm{~km}$ of meridional distance.

served calving periods (typically several decades), but result from the requirement to keep the open ocean part of the model domain sufficiently large.

The climate boundary conditions of increased accumulation rate and ocean temperature for the different climate scenarios are implemented in that the accumulation rate is doubled for scenario II in the ice shelf model forcing file. The ocean model is not directly affected by this. In the case of scenarios III and IV, the increases in ocean temperature are induced by the northern boundary restoring zone where the temperatures are set to the new value. By this procedure, the system slowly attunes to the new boundary condition and passes from a transient phase into a quasi-steady state.

In Fig. 10, the convergence of the coupled model system during the full coupling cycle of 1000 years in total is shown by means of static and dynamic parameters of the part of ice shelf system between
100 and $500 \mathrm{~km}$ of meridional distance. This region is largely unaffected by the fluctuations of ice front position.

The evolution of the total ice shelf mass is characterized by a steady increase of ice mass during the first six coupling cycles (corresponding to 300 years) for the base experiment I (Fig. 10a). The system is in a transient state, showing an asymptotic approach to a stationary state (cf. Section 3). After the first calving event, scenario I depicts a steady increase of total ice shelf mass until the second calving at 600 years. From now on, the system reacts with a temporary decrease in ice mass, but recovers again to the former equilibrium. This also holds for the period after the last calving event at 900 years. The coupled ice shelfocean system can be regarded as a system in quasisteady state conditions. The same situation happens for the climate scenarios II-IV. However, they all have their own equilibrium states, according to the 
change in climatic boundary conditions. Only scenario IV has not reached a quasi-steady state after 1000 years, indicated by a persistent slight decrease in total ice mass.

The evolution of the marine ice mass, formed as a result of the 'ice-pump' process, shows a different behavior (Fig. 10b). Besides ISW formation, this estimation depicts an independent control parameter of the ice shelf-ocean system, indicating extensive interaction between both components of the climate system. The total mass of marine ice increases steadily compared to the total ice shelf mass. This is a result of slow advection and conservation of this quantity, even if its formation process changes locally. Here, a steady state yet has to be reached, however, the portion of total ice volume is only about $2 \%$. Since the initial volume of marine ice mass starts at zero, the build-up of the ice body depends not only on the advective time scale of the ice shelf system alone, but it is influenced by glaciation time-scales. These are typically beyond 1000 years and, therefore, the formation process has not been accomplished in this study.

In Fig. 10c, the evolution in terms of the total kinetic energy of the ice shelf shows the spin-up of the system from the initial state to a transition state (from about year 150). This quantity is influenced by local changes of ice shelf dynamics and, therefore, is sensitive to progressive ice front advance and evolution of the ice body geometry. Beyond 300 years, the system reacts on the different forcing, with each scenario occupying its own kinetic energy level. After calving events, the total kinetic energy abruptly decreases, but recovers again within decades.

The convergence of the total mass loss due to basal melting and of the mass gain due to the accumulation of marine ice is shown for each scenario in Fig. 10d,e, respectively. The basal mass loss of the base experiment I and scenario II (doubling of surface accumulation) is of similar magnitude, but the basal mass gain differs for both experiments. Due to differences in mean ice base slope, which is smaller for scenario II, a diminished rise of super-cooled waters occurs. Hence, the ability of ISW to undershoot the local in situ freezing point temperature, which is the precondition for the formation of marine ice, is reduced. The water mass adjacent to the ice shelf base equilibrates with the freezing point temperature, leading to less marine ice formation. In the ocean warming scenarios III and
IV, strong increases of basal melting lead to an enhanced mass loss, which even doubles for scenario IV compared to the base experiment. However, despite more glacial ice being melted, sub-ice cooling does not chill all warm inflowing waters below the surface freezing point to produce ISW because of meltwater mixing with warmer ambient waters. Consequently, less marine ice forms because less supercooled waters are available. Similar conditions prevail in Pine Island Bay, where very warm Circumpolar Deep Water has direct access to the Pine Island Glacier, leading to enormous melt rates but no significant ISW outflow (Hellmer et al., 1998).

The corresponding states of the coupling components ice thickness and basal melt and freeze rates at the end of the coupling cycles at 1000 years (Fig. 11) show pronounced differences. Compared to the base experiment I, scenario II depicts increased ice thicknesses of about $50, \mathrm{~m}$ on average and a stronger ice front advance of about $100 \mathrm{~km}$. The basal melt rate shows a slight extension of the freezing zone in the north-west corner, but no significant differences are obvious. In contrast, the warming scenarios display an overall ice shelf thinning, mostly pronounced along the eastern inflow. A highly asymmetric zonal ice thickness distribution between develops with thicker ice in the west and thinner ice in the east. At the southeastern corner of the ice shelf, a local anomaly in ice thickness evolves due to upwelling of warm waters near the grounding line, yielding stronger melting.

The patterns of the basal melting/freezing of the scenarios III and IV also show remarkable differences compared to the base experiment. Higher melting in the vicinity of the southern grounding line and along the eastern coast is combined with shrinking of a western freeze pattern in extent and magnitude. The latter has implications for the build up of the marine ice body (Fig. 12). In the base experiment and in scenario II, final thicknesses of up to $150 \mathrm{~m}$, are reached, while for the warming scenarios III and IV maximum thicknesses only amount to about 100 and $70 \mathrm{~m}$, respectively. Besides ISW formation, the existence of marine ice is an conspicuous indicator for intense ice shelf-ocean interaction processes.

As visible from this analysis, ice shelf-ocean interaction has a remarkable impact on the coupled ice shelf-ocean system. In Fig. 13, the effect of changed boundary conditions and corresponding 


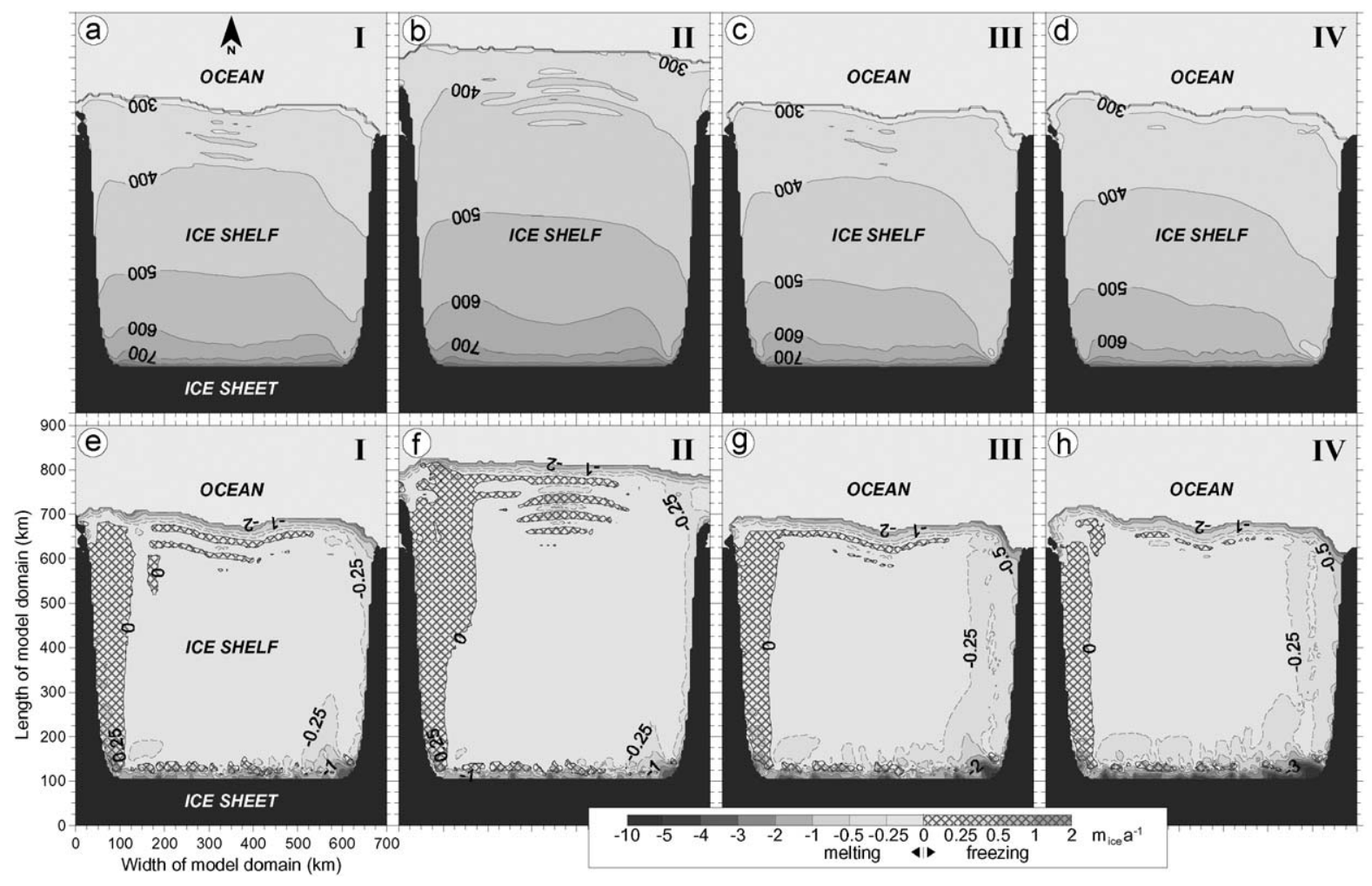

Fig. 11. Final (1000-year state) ice thickness distributions (in $\mathrm{m}$; upper panels) and basal melt and freeze rates (in $\mathrm{m}_{\text {ice }}$ year ${ }^{-1}$; lower panels) for scenarios I (a, e), II (b, f), III (c, g), and IV (d, h), respectively. Zones of strong melting (between 2 and $10 \mathrm{~m}_{\text {ice }}$ year ${ }^{-1}$ ) and local freezing (partly exceeding $1 \mathrm{~m}_{\mathrm{ice}}$ year ${ }^{-1}$ ) near the southern grounding line are induced by the large gradients of the ice shelf draft, causing super-cooling of meltwater within short distances, which leads to marine ice formation at shallower depth. Elongated zones of locally increased basal melting and freezing near the calving front coincide with spurious ice thickness undulations, originating from the approach used to simulate ice front advance.

freshwater fluxes on the water mass composition is shown in temperature-salinity $(\Theta-S)$ diagrams for all scenarios. Only waters beneath the ice front position with a dominant inflow or outflow component are shown. As discussed by Grosfeld et al. (1997), the ice front represents a dynamic barrier for cross-front flow, hence major flow components are steered parallel to the ice front which makes it difficult to address them as clear inflow or outflow components. The water masses in the ice shelf cavity show generally the same distribution along a straight line for the different scenarios. Such a line is defined through mixing of waters at surface freezing point temperature with basal meltwater originating from different depths.

Neglecting heat conduction through the ice, the heat loss by the seawater is proportional to the input of meltwater. Hence, water mass cooling is always associated with freshening, sufficient to give a net reduction in water density. Due to the sloping ice shelf base, the reduction in density sets up a convective circulation, where buoyant ISW rises close to the ice shelf base. Melting and freezing will, therefore, always tend to push the temperature of ISW toward the freezing point temperature at the pressure of the iceocean interface. With this dependency, the temperature of the buoyant ISW varies according to the depth of the ice shelf base.

For the base experiment and scenario II (Fig. $13 a, b)$ the water mass characteristics in the cavity are almost identical. The increased ice thickness for scenario II does not lead to a visible water mass cooling of the outflow compared to scenario I. The reduced slope of the ice shelf base, however, causes 


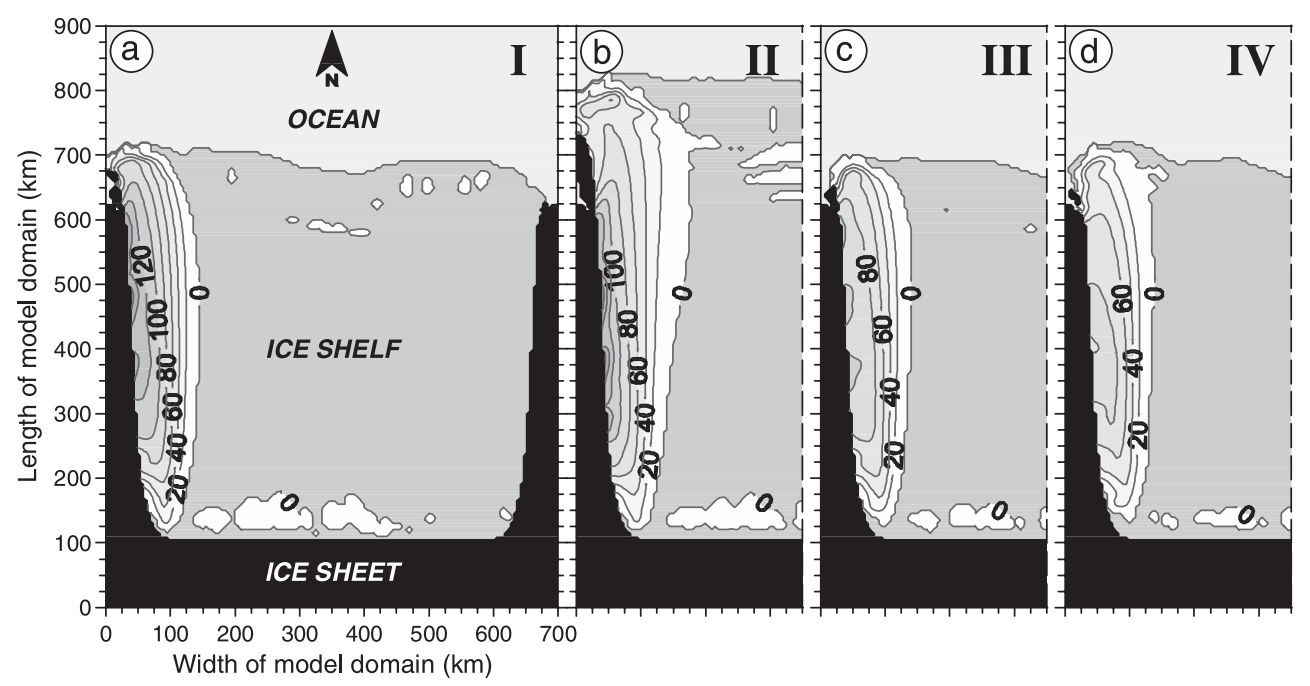

Fig. 12. Thicknesses (in m) of consolidated basal marine ice after 1000 years for scenarios I (a), II (b), III (c), and IV (d), respectively. The eastern ice shelf parts have been omitted in (b)-(d), because distinct marine ice bodies occur only in the west.

an attenuation of the flow within the cavity by about $30 \%$, leading to a significant lower quantity of outflowing waters. Since all waters are by definition assigned to ISW they plot in a close range of the $\Theta-S$ diagram. Mixing of inflowing waters occurs not only between waters at the surface freezing point temperature and glacial meltwater along the theoretical $\Theta-S$ correlation for ISW (Nøst and Foldvik, 1994), but also between neighboring glacial meltwater masses and inflowing warmer waters.

In the case of warming scenarios III and IV spreading of water masses is much higher (Fig. $13 \mathrm{c}, \mathrm{d})$. The inflowing waters show a clear variety in temperature and salinity and a s-shaped form. Mixing between the warmest and saltiest inflowing waters and glacial meltwater leads to a linear distribution. On the other hand, colder and less saline surface and intermediate-depth waters also mix with different varieties of ISW, which leads to the wide spreading between the inflowing more saline and the outflowing less saline components for scenario IV. The aligned characteristic pattern for scenario III represents a uniform water mass distribution close to the slope of the theoretical mixing line. This characteristic spreads when the inflowing waters become warmer in scenario IV. In general, the fraction of ISW exiting the ice shelf cavity reduces in a warming scenario. While the water mass in scenarios I and II are generally cooled through ice shelf-ocean interaction, the outflowing waters in a warming scenario are characterized by a freshwater gain (decrease in salinity). The water masses become less dense due to the increased admixture of glacial meltwaters, leading to a stronger stratification of the water column on the continental shelf. This might have an impact on the propagation of the water masses, flowing over the continental shelf break, in combination with shelf water preconditioning and deep water formation.

\subsection{Validation of final model results for ice shelf thickness and velocity}

The analysis of the model results in view of the present knowledge of ice shelf-ocean system properties reveals a general plausibility of the simulated evolutions of the idealized model system. However, this fundamental but rather qualitative assessment can be supplemented by a more quantitative validation.

For this purpose, ice shelf thickness and velocity profiles along the central meridian of the model domain have been extracted from the final (1000year state) results of the base and climate sensitivity experiments (Fig. 14a,b). These profiles are compared with respective distributions calculated for the same climate scenarios, but for the simplified case of 


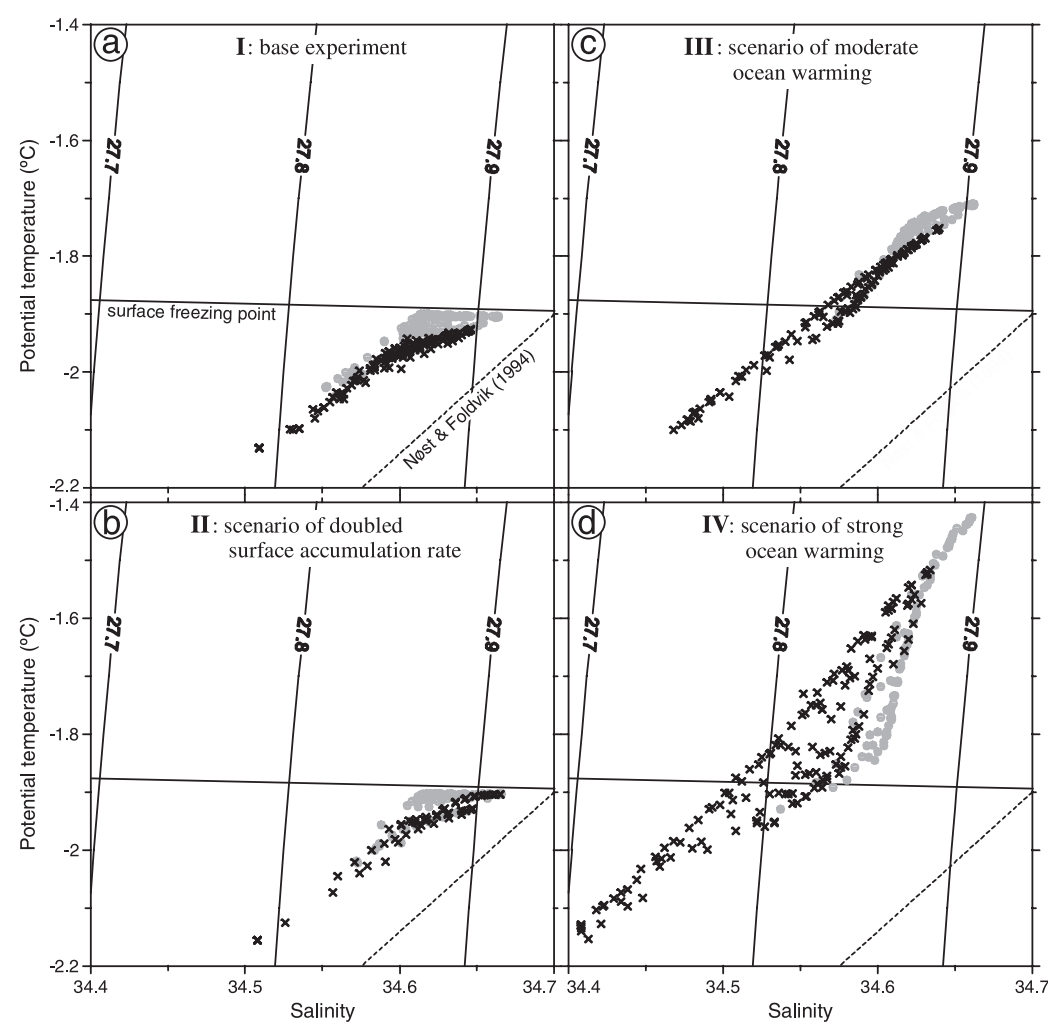

Fig. 13. Potential temperature-salinity $(\Theta-S)$ plots for water masses beneath the ice shelf front for model experiments I to IV. Water masses with a predominant inflow component are indicated as gray filled circles, outflowing components are plotted as crosses. While water masses for scenarios I and II ( $a$ and b) are mainly cooled by melt water gain, the impact of ice shelf-ocean interaction in a warming scenario (c and d) leads to a freshening and spreading of the water mass composition with a shift to lower densities. The dashed line indicates the theoretical $\Theta-S$ correlation for ISW fitted to the observed values of the Filchner-Ronne Ice Shelf region after Nøst and Foldvik (1994). Also shown are the surface freezing point line, and lines of constant potential density $\left(\mathrm{kg} \mathrm{m}^{-3}\right)$ referenced to sea surface.

a uniaxially spreading ice shelf of infinite width (Fig. $14 \mathrm{c}, \mathrm{d})$. Basic preconditions for this comparison are met because: (1) each model experiment shows a nearly stationary evolution of the ice shelf-ocean system in the 1000-year state; (2) associated ice shelf fluxes are directed northward along the central meridian of the model domain, i.e., simulated central flowlines coincide with this meridian; and (3) steady state thickness and velocity profiles of a transversely symmetric ice shelf are calculable analytically for given boundary values (Oerlemans and van der Veen, 1984), which can all be used directly from the respective model experiment data base. Since the analytical solutions for uniaxial ice shelf flow consider constant ice density $\left(\rho=\rho_{\mathrm{c}}\right)$ instead of depthdependent density variations, calculated ice thick- nesses and horizontal velocities are overestimated or underestimated, respectively.

However, the comparison of Fig. 14a,b with c,d shows an obvious analogy between the simulated thickness and velocity profiles of the laterally confined ice shelf in the coupled model system and the respective distributions for the infinitely wide ice shelf for all climate scenarios. In particular, both ice shelf configurations are characterized by maximum ice thicknesses along the central flowline for scenario II. Ice thickness distributions of the other scenarios depict only small differences with tendency to ice body thinning from scenario I to scenarios III and IV (Fig. 14a,c). Identically ordered but more pronounced and with uniform gradations are the corresponding profiles of horizontal ice velocity 


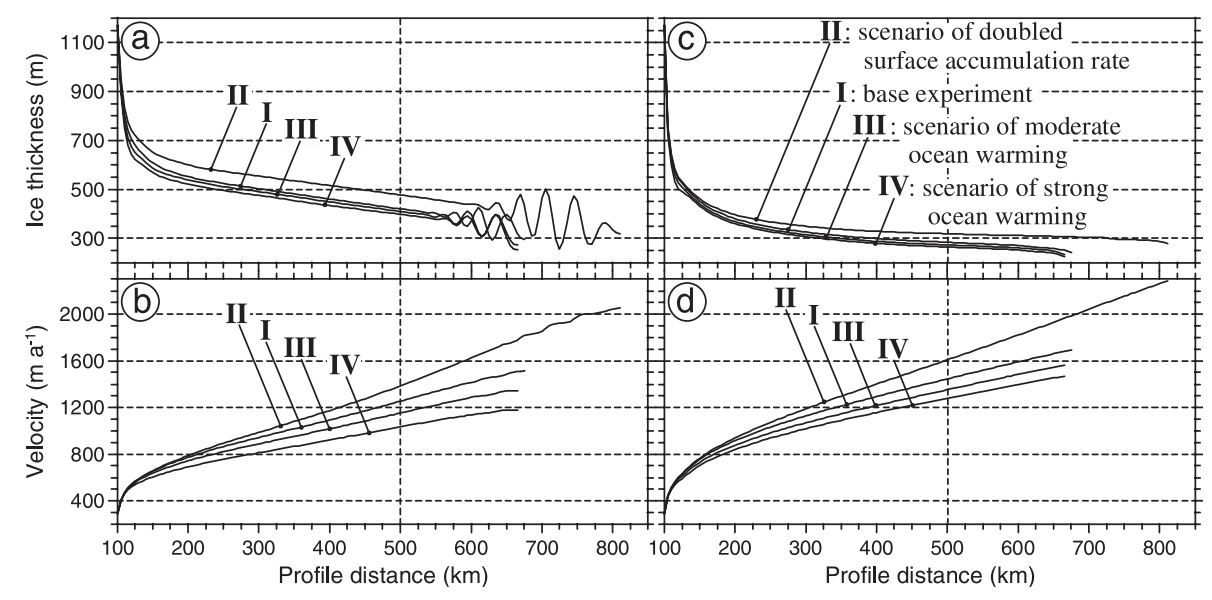

Fig. 14. Model results for the distributions of (a) ice shelf thickness (in $\mathrm{m}$ ) and (b) horizontal ice velocity (in $\mathrm{m}_{\text {year }}{ }^{-1}$ ) along the central line of the coupled ice shelf-ocean system in its 1000-year state. Corresponding (c) thickness and (d) velocity profiles calculated for an uniaxial spreading ice shelf of infinite width, in consideration of climate boundary conditions taken from scenarios I to IV.

along the central flowlines of the two different ice shelf systems (Fig. 14b,d).

Discrepancies between the results for both ice shelf configurations appear in ice thickness and velocity magnitudes derived for each climate scenario. Compared to the analytical calculations for the simplified case, the coupled system with lateral connections of the floating ice to nearly stagnant grounded ice yields significant reductions in both ice shelf thinning and ice velocity increase toward the open ocean. Thus, the stabilizing effect of the adjacent inland ice on the embayed ice shelf is reflected in its geometry and dynamics even along the central flowline. Although, the width of the ice shelf region chosen to be $650 \mathrm{~km}$ is comparatively large.

Furthermore, Fig. 14a accentuates the spurious ice thickness undulations for profile distances $>600 \mathrm{~km}$, which originate from the procedure used to compute ice front advance (see Section 2.1). As indicated also by Figs. $5 \mathrm{c}$ and $11 \mathrm{a}-\mathrm{d}$, the occurrence of these undulations is restricted to the northernmost ice shelf portions adjacent to the calving front which are regularly removed from the model system when calving induced ice front retreat is imposed. Since the overall system evolution is governed mainly by the geometry of the central and southern parts of the ice shelf and the cavity underneath as well as by the ice and ocean dynamics in these regions, the spurious thickness undulation are of no significance for our model study. Moreover, the good correlation between the (quasi-) steady state profiles of the laterally confined and the infinitely wide ice shelves for the different climate scenarios argues for a general reliability of the results attained by the coupled applications of the ice shelf and ocean models.

\section{Summary and conclusions}

We have developed a coupled ice shelf-ocean model system to investigate the main feedback mechanisms between both components, their interactive response to changes in boundary conditions, and the overall system evolution under different climate scenarios. Since ice shelves provide the only extensive direct interface particularly between the Antarctic Ice Sheet and the surrounding Southern Ocean, they represent sensitive key regions of the global climate system.

Our numerical experiments are based on coupled applications of two established 3D-stand-alone models for the simulations of ice shelf dynamics and ocean circulation. This allows us to consider the individual components in their full complexity. The common quantities influential for both climate components are ice shelf geometry and basal mass exchange. Updated data sets of these parameters are transferred to a coupling module which controls the coordinate trans- 
formation and interpolation between both model grids. Time-dependent simulations are performed with a 50-year coupling cycle. The individual components continuously adapt to the actual boundary conditions, while the evolution of the coupled ice shelf-ocean system converges directly toward its steady state for the selected climate scenario.

To ensure reliable long-term simulations, both model components need to include the mechanism or rather the impact of the characteristic alternations between steady ice front advance and sudden retreat due to tabular iceberg break offs. Our modeling of such calving processes is based on the hypothesis of abrupt crack propagation along significant elongated anomalies in the computed distribution of the second principal horizontal deviatoric stress. Although this approach is neither theoretically founded nor empirically described, it provides for glaciological plausible results.

The base experiment (scenario I) shows the evolution of the ice shelf-ocean system from an artificially chosen initial state. The setup for geometry and boundary conditions is comparable to the configuration of the Filchner-Ronne Ice Shelf region, but adequately idealized to focus on the principal exchange processes and reactions of the coupled system, rather than to deal with system peculiarities of such a complex regime. During initial phase (up to about 150 years), fundamental changes in ice shelf shape and basal mass balance are subject to the redistribution of ice shelf mass, according to ice dynamics, and the adjustment of the oceanic regime. After 300 years, ice thicknesses have been largely adapted to the boundary conditions, and the ice shelf-ocean system continuously converges to a steady state. A marine ice body develops at the western grounding line during integration. Despite the idealized character of our model system, final results show similarities to real ice shelf systems. In particular, maximum ice velocities of about $1400 \mathrm{~m}$ year $^{-1}$ and extended marine ice bodies are also observed for the FRIS.

To asses the sensitivity of ice shelf-ocean systems to climate changes, three experiments have been conducted, regarding the influence of increased surface accumulation (scenario II) and ocean warming at rates of $0.2{ }^{\circ} \mathrm{C}$ (scenario III) and $0.5^{\circ} \mathrm{C}$ (scenario IV). Although these scenarios are partly at the lower limit of IPCC discussions, they all show sensitivities and conspicuous reactions of the coupled ice shelf-ocean system.

Increased surface accumulation leads to a thickening of the ice shelf and, therefore, has an impact on the water mass circulation of the ice shelf cavity. The freshwater flux due to basal melting is not altered, but the amount of basal freezing is reduced. This is a reaction of the reduced slope of the ice shelf base. In the case of ocean warming, the ice shelf is subject to a dramatic change. For ocean temperatures only $0.2{ }^{\circ} \mathrm{C}$ higher, the mean basal melt rate increases by $50 \%$. Ice shelf thinning corresponds to the inflow of open ocean waters with a less reaction in the outflow region. A highly asymmetric ice thickness distribution develops which influences the whole ice shelf system. The asymmetry even increases for scenario IV, in which basal mass loss doubles compared to the base experiment. Consequently, the water masses in the cavity are less dense and warmer. The fraction of ISW in the meltwater plume reduces, although the basal melting increases. A strongly increased stratification of the outflowing waters results. This might be important for water mass formation at the continental slope, leading to changes in deep and bottom water formation.

Although, our ocean warming scenarios are weak compared to IPCC studies, which imply warming up to $2.5{ }^{\circ} \mathrm{C}$ for the Southern Ocean's upper $750 \mathrm{~m}$ (O'Farrell et al., 1997), we find that the resulting enhanced basal melting leads to significant ice shelf thinning. In particular, ice shelf regions directly exposed to ocean inflow react within short time-scales (decades to centuries). Since ice shelves are assumed to contribute to the stability of the adjoining inland ice (ISMASS Committee, this volume), ice shelf response to ocean warming, which is a consequence of atmospheric greenhouse warming, seems to be a main crucial factor especially in respect of the possible future development of the marine based West Antarctic Ice Sheet. This comprises the world's two largest ice shelf regions, the Filchner-Ronne and Ross Ice Shelves, which are subject to intense interactions with the ocean and, therefore, are assessed to be highly vulnerable to changes in climate boundary conditions.

Thus, as a next step, our coupled model approach will be applied to realistic ice shelf-ocean systems to investigate their reaction to global change scenarios. These future model studies should include additionally grounded regions like ice rises and ice rumples 
within ice shelves, the determination of tabular iceberg calving dates as well as the estimation of calving cycle periodicities. The proposed approach to simulate calving induced ice front retreats is an auspicious basis for the development of a thorough formulation to be implemented directly in ice shelf models. With the described coupled model system, a new tool is given to evaluate the impact of climate warming on Antarctica and the Southern Ocean at the ice shelfocean interface as possible input for large-scale climate models.

\section{Acknowledgements}

This work was partly performed at the University of Münster within the frame of the German CLIVAR/ marin project (grant no. 03F0246F3) founded by the German Federal Ministry of Education and Research (bmbf). We are grateful to Manfred A. Lange, University of Münster, for his continuous encouragement and support in this research and the common initiation of the project together with K.G.. We thank H.H. Hellmer for providing constructive suggestions to the paper. The authors appreciate very much the careful reading and suggestions of two anonymous reviewers which helped to improve the manuscript.

\section{References}

Blatter, H., 1995. Velocity and stress fields in grounded glaciers: a simple algorithm for including deviatoric stress gradients. J. Glaciol. 41 (138), 333-344.

Bryan, K., 1969. A numerical method for the study of the circulation of the world ocean. J. Comput. Phys. 4, 347-376.

Budd, W.F., Jenssen, D., Mavrakis, E., Coutts, B., 1994. Modelling the Antarctic ice-sheet changes through time. Ann. Glaciol. 20, 291-297.

Cox, M.D., 1984. A primitive equation, 3-dimensional model of the ocean. GFDL Ocean Group Tech. Rep. 1, Geophys. Fluid Dyn. Lab. Princeton Univ., Princeton, NJ.

Determann, J., 1991. Numerical modelling of ice shelf dynamics. Antarct. Sci. 3 (2), 187-195.

Determann, J., Gerdes, R., 1994. Melting and freezing beneath ice shelves: implications from a three-dimensional ocean-circulation model. Ann. Glaciol. 20, 413-419.

Doake, C.S.M., Corr, H.F.J., Rott, H., Skvarca, P., Young, N.W., 1998. Breakup and conditions for stability of the northern Larsen Ice Shelf, Antarctica. Nature 391, 778-780.
Foldvik, A., Kvinge, T., 1974. Conditional instability of sea water at the freezing point. Deep-Sea Res. 21, 169-174.

Foldvik, A., Gammelsrød, T., Tørresen, T., 1985. Circulation and water masses on the southern Weddell Sea shelf. In: Jacobs, S.S. (Ed.), Oceanology of the Antarctic Continental Shelf. Antarct. Res. Ser., vol. 43. AGU, Washington, DC, pp. 5-20.

Gerdes, R., 1993. A primitive equation ocean circulation model using a general vertical coordinate transformation: 1 . Description and testing of the model. J. Geophys. Res. 98 (C8), 14683-14701.

Gerdes, R., Determann, J., Grosfeld, K., 1999. Ocean circulation beneath Filchner-Ronne Ice Shelf from three-dimensional model results. J. Geophys. Res. 104 (C7), 15827-15842.

Grosfeld, K., 1993. Untersuchungen zu Temperaturregime und Massenhaushalt des Filchner-Ronne-Schelfeises, Antarktis, unter besonderer Berücksichtigung von Anfrier- und Abschmelzprozessen. Ber. z. Polarf., vol. 130. Alfred-WegenerInstitut für Polar-und Meeresforschung, Bremerhaven, Germany, p. 148.

Grosfeld, K., Gerdes, R., 1998. Circulation beneath the Filchner Ice Shelf, Antarctica, and its sensitivity to changes in the oceanic environment: a case study. Ann. Glaciol. 27, 99-104.

Grosfeld, K., Gerdes, R., Determann, J., 1997. Thermohaline circulation and interaction between ice shelf cavities and the adjacent open ocean. J. Geophys. Res. 102 (C7), 15595-15610.

Grosfeld, K., Hellmer, H.H., Jonas, M., Sandhäger, H., Schulte, M., Vaughan, D.G., 1998. Marine ice beneath Filchner ice shelf: evidence from a multi-disciplinary approach. In: Jacobs, S.S., Weiss, R.F. (Eds.), Ocean, Ice and Atmosphere, Interaction at the Antarctic Continental Margin. Antarct. Res. Ser., vol. 75. AGU, Washington, DC, pp. 319-339.

Hellmer, H.H., Jacobs, S.S., 1995. Seasonal circulation under the eastern Ross Ice Shelf, Antarctica. J. Geophys. Res. 100 (C6), $10873-10885$.

Hellmer, H.H., Olbers, D.J., 1989. A two-dimensional model for the thermohaline circulation under an ice shelf. Antarct. Sci. 1, $325-336$.

Hellmer, H.H., Jacobs, S.S., Jenkins, A., 1998. Oceanic erosion of a floating Antarctic glacier in the Amundsen Sea. In: Jacobs, S.S., Weiss, R.F. (Eds.), Ocean, Ice and Atmosphere, Interaction at the Antarctic Continental Margin. Antarct. Res. Ser., vol. 75. AGU, Washington, DC, pp. 83-99.

Herterich, K., 1987. On the flow within the transition zone between ice sheet and ice shelf. In: van der Veen, C.J., Oerlemans, J. (Eds.), Dynamics of the West Antarctic Ice Sheet. D. Reidel, Dordrecht, pp. 185-202.

Holland, D.M., Jenkins, A., 1999. Modelling thermodynamic iceocean interactions at the base of an ice shelf. J. Phys. Oceanogr. 29, 1787-1800.

Huybrechts, P., 1992. The Antarctic ice sheet and environmental change: a three-dimensional modelling study. Ber. z. Polarf., vol. 99. Alfred-Wegener-Institut für Polar-und Meeresforschung, Bremerhaven, Germany, p. 241.

Jacobs, S.S., Fairbanks, R.G., Horibe, Y., 1985. Origin and evolution of water masses near the Antarctic continental margin: evidence from $\mathrm{H}_{2}^{18} \mathrm{O} / \mathrm{H}_{2}^{16} \mathrm{O}$ ratios in seawater. In: Jacobs, S.S. (Ed.), Oceanology of the Antarctic Continental Shelf. Antarct. Res. Ser., vol. 43. AGU, Washington, DC, pp. 59-85. 
Jacobs, S.S., Hellmer, H.H., Doake, C.S.M., Jenkins, A., Frolich, R.M., 1992. Melting of ice shelves and the mass balance of Antarctica. J. Glaciol. 38 (136), 375-387.

Jacobs, S.S., Hellmer, H.H., Jenkins, A., 1996. Antarctic ice sheet melting in the Southeast Pacific. Geophys. Res. Lett. 23 (9), 957-960.

Jenkins, A., 1991. A one-dimensional model of ice shelf-ocean interaction. J. Geophys. Res. 96 (C11), 20667-20671.

Jenkins, A., Bombosch, A., 1995. Modelling the effect of frazil ice crystals on the dynamics and thermodynamics of ice shelf water plumes. J. Geophys. Res. 100 (C4), 6967-6981.

Jenkins, A., Doake, C.S.M., 1991. Ice-ocean interaction on Ronne ice shelf, Antarctica. J. Geophys. Res. 96 (C1), 791-813.

Leggett, J., Pepper, W.J., Swart, R.J., 1992. Emissions scenarios for IPCC: an update. In: Houghton, J.T., Callander, B.A., Varney, S.K. (Eds.), Climate Change 1992: The Supplementary Report to the IPCC Scientific Assessment. Cambridge Univ. Press, Cambridge, pp. 69-95.

Lewis, E.L., Perkin, R.G., 1986. Ice pumps and their rates. J. Geophys. Res. 91 (C10), 11756-11762.

Lingle, C.S., Schilling, D.H., Fastook, J.L., Paterson, W.S.B., Brown, T.J., 1991. A flow band model of the Ross ice shelf, Antarctica: response to $\mathrm{CO}_{2}$-induced climatic warming. J. Geophys. Res. 96 (B4), 6849-6871.

MacAyeal, D.R., 1992. Irregular oscillations of the West Antarctic Ice Sheet. Nature 359, 29-32.

MacAyeal, D.R., Shabtaie, S., Bentley, C.R., King, S.D., 1986. Formulation of ice shelf dynamic boundary conditions in terms of a Coulomb rheology. J. Geophys. Res. 91 (B8), 8177-8191.

Manabe, S., Stouffer, R.J., 1994. Multiple-century response of a coupled ocean-atmosphere model to an increase of atmospheric carbon dioxide. J. Clim. 7, 5-23.

Mayer, C., 1996. Numerische Modellierung der Übergangszone zwischen Eisschild und Schelfeis. Ber. z. Polarf., vol. 214. Alfred-Wegener-Institut für Polar-und Meeresforschung, Bremerhaven, Germany, p. 150.

Mellor, G.L., 1991. An equation of state for numerical models of oceans and estuaries. J. Atmos. Ocean. Technol. 8 (4), 609-611.

Morris, E.M., Vaughan, D.G., 1994. Snow surface temperatures in West Antarctica. Antarct. Sci. 6 (4), 529-535.

Nøst, O.A., Foldvik, A., 1994. A model of ice shelf-ocean interaction with application to the Filchner-Ronne and the Ross Ice Shelves. J. Geophys. Res. 99 (C7), 14243-14254

Oerlemans, J., van der Veen, C.J., 1984. Ice Sheets and Climate. D. Reidel, Dordrecht, Holland.

Oerter, H., Kipfstuhl, J., Determann, J., Miller, H., Wagenbach, D., Minikin, A., Graf, W., 1992. Evidence for basal marine ice in the Filchner-Ronne Ice Shelf. Nature 358, 399-401.

O’Farrell, S.P., McGregor, J.L., Rotstayn, L.D., Budd, W.F., Zweck,
C., Warner, R., 1997. Impact of transient increases in atmospheric $\mathrm{CO}_{2}$ on the accumulation and mass balance of the Antarctic Ice Sheet. Ann. Glaciol. 25, 137-144.

Oppenheimer, M., 1998. Global warming and the stability of the West Antarctic Ice Sheet. Nature 393, 325-332.

Paterson, W.S.B., 1994. The Physics of Glaciers, 3rd ed. Pergamon/ Elsevier, Oxford.

Robin, G. de Q., 1979. Formation, flow and disintegration of ice shelves. J. Glaciol. 24, 259-271.

Sandhäger, H., 2000. Quantifizierung eisdynamischer und massenhaushaltsrelevanter Basisgrößen eines antarktischen InlandeisSchelfeis-Systems unter Einsatz eines numerischen Fließmodells. Ph.D. thesis, Westfälische Wilhelms-Universität Münster, Germany, p. 232.

Thyssen, F., 1988. Special aspects of the central part of FilchnerRonne Ice Shelf, Antarctica. Ann. Glaciol. 11, 173-179.

Thyssen, F., Bombosch, A., Sandhäger, H., 1992. Elevation, ice thickness and structure mark maps of the central part of the Filchner-Ronne Ice Shelf, Antarctica. Polarforschung 62 (1), $17-26$.

Vaughan, D.G., Doake, C.S.M., 1996. Recent atmospheric warming and retreat of ice shelves on the Antarctic Peninsula. Nature $379,328-331$.

Vaughan, D.G., Jonas, M., 1996. Measurements of velocity of Filchner-Ronne Ice Shelf. In: Oerter, H. (Ed.), FilchnerRonne Ice Shelf Programme Report, vol. 10. Alfred Wegener Institute for Polar and Marine Research, Bremerhaven, pp. $111-116$.

Warrick, R.A., Le Provost, C., Meier, M.F., Oerlemans, J., Woodworth, P.L., 1995. Changes in sea level. In: Houghton, J.T., Meria Filho, L.G., Callander, B.A., Harris, N., Kattenberg, A., Maxkell, K. (Eds.), Climate Change 1995: The Science of Climate Change. Cambridge Univ. Press, Cambridge, pp. 359-405.

Weertman, J., 1957. Deformation of floating ice shelves. J. Glaciol. 3 (21), 38-42.

Williams, M.J.M., Jenkins, A., Determann, J., 1998a. Physical controls on ocean circulation beneath ice shelves revealed by numerical models. In: Jacobs, S.S., Weiss, R.F. (Eds.), Ocean, Ice and Atmosphere, Interaction at the Antarctic Continental Margin. Antarct. Res. Ser., vol. 75. AGU, Washington, DC, pp. $285-299$.

Williams, M.J.M., Warner, R.C., Budd, W.F., 1998b. The effects of ocean warming on the melting and ocean circulation under the Amery Ice Shelf, East Antarctica. Ann. Glaciol. 27, $75-80$.

Williams, M.J.M., Warner, R.C., Budd, W.F., 2002. Sensitivity of the Amery Ice Shelf, Antarctica, to changes in the climate of the Southern Ocean. J. Clim. 15, 2740-2757. 